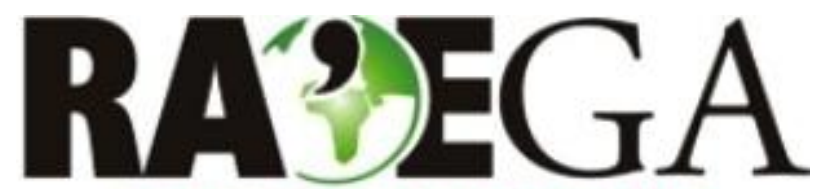

O ESPACYO GEOGRÁFICO EM ANÁLISE

\title{
A PERCEPÇÃO DOS PRATICANTES DE ATIVIDADE FÍSICA SOBRE A QUALIDADE AMBIENTAL SONORA DOS PARQUES PÚBLICOS DE CURITIBA-PARANÁ
}

\section{THE PERCEPTION OF PRACTITIONERS OF PHYSICAL ACTIVITY ON ENVIRONMENTAL SOUND QUALITY OF PUBLIC PARKS IN CURITIBA-PARANÁ}

\author{
Bani Szeremeta \\ Professor da rede pública do Estado do $P R$ \\ Curitiba, $P R$ \\ e-mail: banibio@yahoo.com.br \\ Paulo Henrique Zannin \\ Professor da Universidade Federal do Paraná (UFPR) \\ Departamento de Mecânica \\ Curitiba, $P R$ \\ e-mail: zannin@ufpr.br
}

\section{Recebido em: 27/02/2013}

Aceito em: 19/08/2014

\section{Resumo}

O objetivo desta pesquisa foi analisar a percepção dos praticantes de atividade física sobre a qualidade ambiental sonora dos parques públicos de Curitiba - Paraná. Foram selecionados quatro parques: três destes localizados muito próximos e/ou cercados por vias de intenso tráfego de veículos e um situado em região mais tranquila, o qual foi considerado como área controle. Foram realizadas 328 entrevistas com os usuários destas áreas (82 em cada parque), medições acústicas e mapeamento acústico. Confirmou-se a grande influência do ruído do tráfego intenso de veículos no ambiente sonoro dos parques, onde a maioria dos pontos e regiões que apresentam níveis sonoros que excederam o limite imposto pela lei municipal de Curitiba (55 dB[A]) estão no perímetro dos parques, próximos das vias de grande movimentação. Como esperado apenas a área controle apresentou valor médio de nível de pressão sonora de acordo com a legislação local e uma boa qualidade do ambiente sonoro conforme a percepção dos usuários. Também foram 


\title{
A PERCEPÇÃO DOS PRATICANTES DE ATIVIDADE FÍSICA SOBRE A QUALIDADE AMBIENTAL SONORA DOS PARQUES PÚBLICOS DE CURITIBA-PARANÁ
}

identificadas outras condições no ambiente, além dos níveis de pressão sonora e forma urbana do entorno, que interferem conjuntamente na paisagem sonora dos parques e na sua percepção pelos frequentadores, tais como: o grau de incômodo ao ruído de trânsito, os tipos de sons que integram a paisagem sonora, a paisagem visual, as expectativas dos usuários aos sons, e os locais das estruturas dos equipamentos de lazer e atividade física.

Palavras-chave: Ambiente, Parques, Atividade Física, Saúde, Ruído, Mapeamento do ruído.

\begin{abstract}
The aim of this study was to analyze the perception of the physically active people on the environmental sound quality of public parks of Curitiba - Paraná. We selected four parks: three of these are located in close proximity and/or pathways surrounded by intense vehicle traffic. The fourth one is situated in a more peaceful area, considered as the control area. Three hundred and twenty eight interviews were conducted with users of these areas (82 in each park), acoustic noise measurements and noise mapping were also conducted. Data confirmed the strong influence of traffic noise from vehicles in the sound environment of the parks, where most of the points and areas with noise levels that exceed the limit imposed by the municipal law of Curitiba (55 dB(A)) are on the perimeter parks, near major routes of movement. As expected, only the control park displayed sound pressure levels in accordance with local legislation and good environmental noise quality as perceived by its users. Other conditions and parameters of the environment, beyond the sound pressure levels and the surrounding urban form, were also taken into account, and which interfere on the soundscape of the parks and in its perception by patrons. These parameters were: the degree of nuisance caused by noise of traffic, the types of sounds that make up the soundscape, the visual landscape, users' expectations to the sounds, and the local structures of leisure and physical activity.
\end{abstract}

Keywords: Environment, Parks, Physical activity, Health, Noise, Noise mapping.

\section{INTRODUÇÃo}

A prática regular de atividade física é um importante fator para uma melhor qualidade de vida, uma vez que estabelece benefícios à saúde física e mental e diminui o risco de doenças crônicas não transmissíveis (diabetes, hipertensão, osteoporose, neoplasias, etc.) (BERLIN et al, 1990; BLAIR et al, 1995; KOHL, 2001; BAUMAN, 2004; WARBURTON et al, 2006). No entanto, o avanço tecnológico associado ao desenfreado crescimento urbano e a redução de áreas verdes têm contribuído para uma população de estilo de vida sedentário e colaborado para a 


\section{A PERCEPÇÃO DOS PRATICANTES DE ATIVIDADE FÍSICA SOBRE A QUALIDADE AMBIENTAL SONORA DOS PARQUES PÚBLICOS DE CURITIBA-PARANÁ}

expansão de ambientes degradados, insalubres ou sem conforto (HASKELL et al, 2007).

Neste contexto, alguns estudos mostram que a boa qualidade social e física de parques urbanos, como por exemplo, infraestrutura adequada, segurança, facilidade de acesso, baixa poluição, e outros fatores positivos, aumentam a possibilidade de frequência das pessoas e, por conseguinte, um comportamento fisicamente ativo (REIS, 2001; FISHER et al, 2004; BEDIMORUNG-RUNG, 2005; HORNIG, 2005; SALLIS, 2006; BAKER, 2008; COLLET et al, 2008; CASSOU, 2009; TESTER et al, 2009; COHEN, 2010). Deste modo, condições ambientais adequadas são determinantes na utilização de parques para o desenvolvimento de atividades físicas e o lazer. O que pode contribuir na redução da prevalência de sedentarismo e auxiliar na promoção da saúde e bem estar, além de possibilitar o aumento do nível de atividade física dos ativos. Em contrapartida, a má qualidade do ambiente e a insatisfação dos usuários são determinantes ambientais negativos para o uso dos parques, de forma a vir descaracterizar estas funções associadas à qualidade de vida e saúde pública.

A cidade de Curitiba apresenta expressividade no número de implantações de áreas verdes nos últimos anos (SMMA, 2010). Por exemplo, em 1988 eram apenas cinco parques públicos, atualmente são vinte e dois (IPPUC, 2013). Entretanto, além destas áreas serem direcionadas para o lazer e outras atividades destinadas à visitação, foram planejadas prioritariamente para impedirem a habitação nos fundos de vale e regularem a vazão de rios (MENEZES, 1996). Em razão destas necessidades prioritárias, de acordo com Reis (2001), muitos dos parques se situam em regiões que nem sempre suprem as características almejadas pelos seus visitantes, como acesso facilitado e um ambiente apropriado para a realização de atividades. Assim, muitos parques se situam em regiões de saturação urbana e, então, muito próximos ou circundados por vias de intenso tráfego veicular, expostos a poluição sonora.

Esta condição ambiental pode prejudicar o conforto acústico e/ou a percepção positiva do ambiente, e, consequentemente, influenciar de forma negativa no 


\section{A PERCEPÇÃO DOS PRATICANTES DE ATIVIDADE FÍSICA SOBRE A QUALIDADE AMBIENTAL SONORA DOS PARQUES PÚBLICOS DE CURITIBA-PARANÁ}

comportamento de utilização para o lazer e a prática de atividades físicas. Também pode colaborar com a hipótese de minimizar ou bloquear os benefícios psicológicos que o contato com estes ambientes podem trazer durante a realização destas atividades, haja vista, que nos grandes centros urbanos, o ruído do trânsito de veículos automotores é o principal componente de incômodo (SATO et al, 1999; PAZ et al, 2005). No Brasil, este fato pode ser intensificado através da popularização e facilidade de crédito na compra de veículos, assim como pelo aumento da população, deficiências no planejamento urbano e na fiscalização ambiental.

Deste modo, o presente estudo se propõe a analisar o ambiente sonoro de parques urbanos por meio de uma abordagem holística, considerando-se o conceito de paisagem sonora (soundscape) estabelecido por Schafer (2001). De acordo com o autor, o processo para caracterizar a paisagem sonora de um determinado local não se restringe ao levantamento dos níveis de ruído de tráfego veicular. Mas sim, a conectividade deste tipo de levantamento a outros métodos de percepção do ambiente sonoro que podem ser realizados por meio de entrevistas, identificação de fatores espaciais (geomorfologia, ambiente construído, etc.) e levantamentos de tipos de sons desagradáveis e agradáveis.

Assim, o ambiente sonoro não é avaliado unicamente através de estímulos mensuráveis, mas também por parâmetros sensíveis, como a percepção e representações individuais desse ambiente, além dos vários outros fatores nele presentes (PEREIRA, 2003). Por conseguinte, é possível se saber com maior eficiência quais os sons que devem ou não ser preservados no ambiente urbano, a relação destes com a tipologia da área que estão inseridos e a forma como a comunidade percebe a paisagem sonora.

Por fim, considerando-se a importância da qualidade ambiental dos parques públicos na promoção da atividade física, saúde e qualidade de vida, e a problemática do ruído ambiental urbano como fonte de incômodo, a presente pesquisa se propôs a analisar a percepção da qualidade ambiental sonora de praticantes de atividade física e verificar se os parques encontram-se acusticamente poluídos. Ainda foi investigado, com auxílio de mapeamento acústico, se os 


\section{A PERCEPÇÃO DOS PRATICANTES DE ATIVIDADE FÍSICA SOBRE A QUALIDADE AMBIENTAL SONORA DOS PARQUES PÚBLICOS DE CURITIBA-PARANÁ}

equipamentos de ginástica e lazer (quadras esportivas, equipamentos para flexões de braço e perna, alongamento, abdominais, simuladores de caminhada e playground) se encontram em locais expostos ao ruído ambiental do entorno imediato. Assim, espera-se apresentar subsídios para projetos que visem melhorar o ambiente destes espaços públicos, tornando-os mais atrativos para a atividade física e o lazer.

\section{MATERIAIS E MÉTODOS}

\section{1. Áreas de estudo}

A cidade de Curitiba possui atualmente vinte e dois parques (Figura 1), o que torna inviável a coleta de dados em todos estes locais (IPPUC, 2010). Isto gerou a necessidade de serem estabelecidos critérios de seleção das áreas.

O principal critério de inclusão, baseia-se no fato de alguns parques estarem situados em áreas de grande adensamento urbano, circundados por vias de intenso tráfego veicular (ZANNIN et al, 2003; SZEREMETA \& ZANNIN, 2009), havendo a hipótese do descumprimento da lei municipal 10625, que estabelece o nível de ruído máximo permissível para áreas verdes (AV) no período diurno de $55 \mathrm{~dB}(\mathrm{~A})$, e o possível incômodo dos usuários destas áreas.

Ainda, outros critérios foram estabelecidos para a escolha das áreas de estudo, tais como: existência de equipamentos para a realização de exercícios; existência de equipamentos de lazer; e por último, as condições de segurança dos locais com o objetivo de zelar pela integridade física dos entrevistadores ou não coibi-los na realização do procedimento.

Assim, foram escolhidos quatro parques da cidade: três situados muito próximos e praticamente cercados por vias de intenso tráfego de veículos e um quarto parque localizado mais distante destas vias, em região considerada mais tranquila (área controle): Passeio Público, São Lourenço, General Iberê de Mattos (Bacacheri; área controle) e Jardim Botânico (Tabela 1). Por meio da comparação destes dois tipos de contextos urbanos foi possível avaliar a influência da forma urbana do entorno no ambiente sonoro destas áreas, considerando-se tanto a 


\section{A PERCEPÇÃO DOS PRATICANTES DE ATIVIDADE FÍSICA SOBRE A QUALIDADE AMBIENTAL SONORA DOS PARQUES PÚBLICOS DE CURITIBA-PARANÁ}

propagação do ruído ambiental quanto a percepção sonora dos usuários destas áreas.

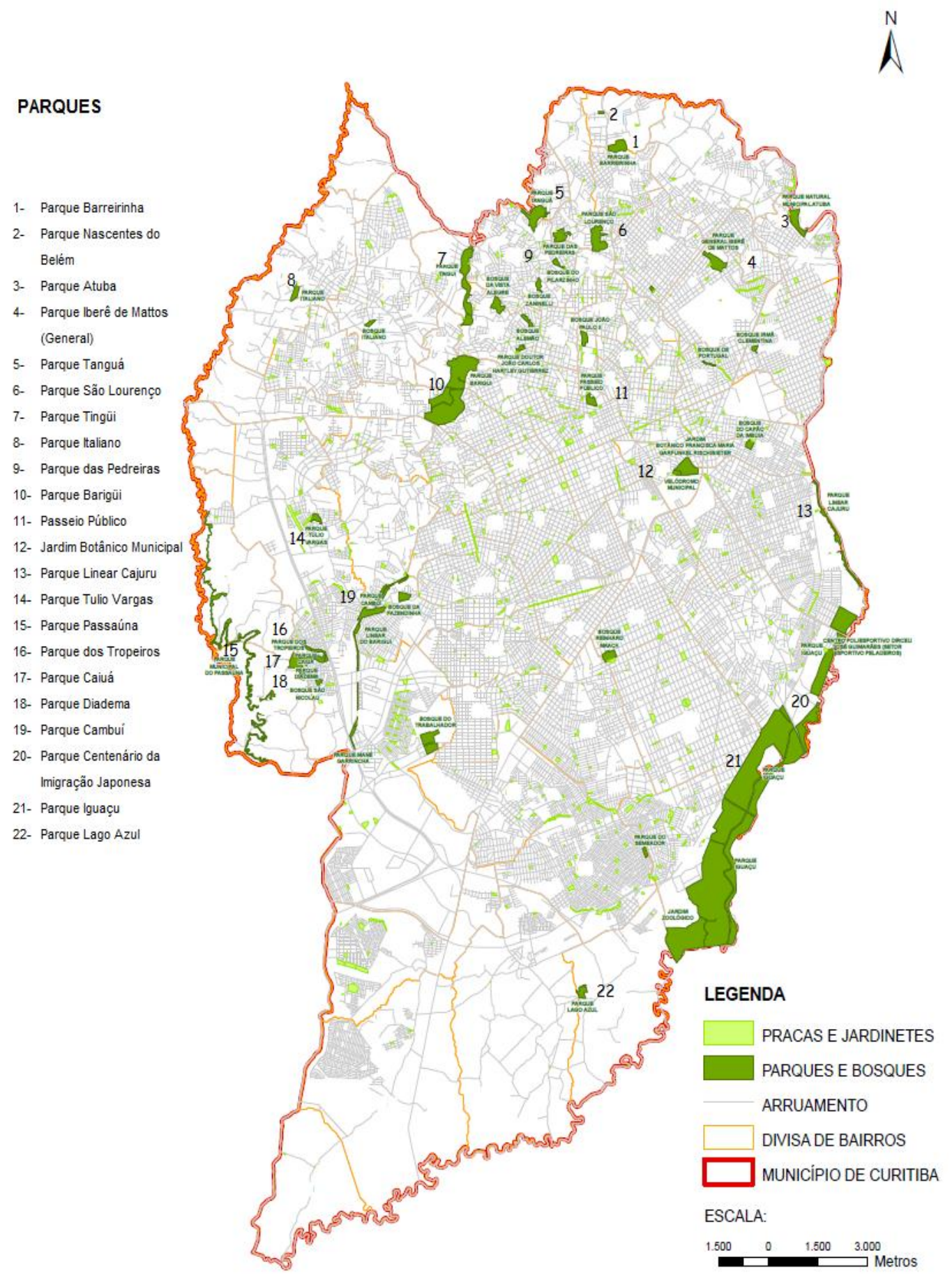

Figura 1: Mapa de Localização de Parques, Bosques, Praças e Jardinetes de Curitiba-PR. Fonte: IPPUC, 2012. Modificado por Szeremeta em 2014. 


\section{A PERCEPÇÃO DOS PRATICANTES DE ATIVIDADE FÍSICA SOBRE A QUALIDADE AMBIENTAL SONORA DOS PARQUES PÚBLICOS DE CURITIBA-PARANÁ}

Tabela 1: Área dos parques listados de acordo com o ano de fundação

\begin{tabular}{cccc}
\hline Parque Urbano & Ano de Fundação & Área $\left(\mathrm{m}^{2}\right)$ & Distância do Centro \\
\hline Passeio Público & 1886 & 69.285 & No Centro \\
São Lourenço & 1972 & 203.000 & $3.5 \mathrm{Km}$ \\
General Iberê de Mattos (Bacacheri) & 1988 & 152.000 & $6.0 \mathrm{Km}$ \\
Jardim Botânico & 1991 & 270.000 & $2.5 \mathrm{Km}$ \\
\hline
\end{tabular}

Fonte: IPPUC, 2010

\subsection{Instrumentos e procedimentos para coleta de dados}

\subsubsection{Medições acústicas}

As medições acústicas visaram avaliar e analisar o ambiente sonoro dos parques como um todo. Para realização desse procedimento foram adotados os passos descritos a seguir.

As avaliações foram feitas nas trilhas ou pistas (tipo ciclovia) por onde os frequentadores circulam e/ou desenvolvem suas atividades (área útil). Assim, a locação e quantidade de pontos medidos ( 6 a 9 em cada parque) foram definidos de modo que fossem distribuídos uniformemente na área interna dos parques e que representassem os locais de permanência e caminho dos usuários (amostra não aleatória), buscando-se, assim, padronização e o melhor controle para a veracidade dos dados. Os níveis sonoros foram mensurados e processados pelo decibelímetro modelo 2238 da marca Brüel e Kjaer que tem a capacidade de efetuar simultaneamente várias medições de diferentes descritores acústicos. Para a realização deste estudo, o cálculo adotado para a análise dos resultados foi o do nível equivalente médio $\left(L_{\text {Aeq }}\right)$, que é o nível médio de pressão sonora durante o período de medição.

Todas as avaliações foram realizadas em dias úteis da semana (segunda a sexta feira), durante os meses de novembro e dezembro de 2011 e no período entre as $17 \mathrm{~h}$ e $19 \mathrm{~h}$, considerado o horário em que há maior tráfego de veículos no entorno dos parques (horário de "pico"). Neste período também é evidente o aumento no número de visitantes que utilizam os parques para a realização de atividade física durante a semana. 


\section{A PERCEPÇÃO DOS PRATICANTES DE ATIVIDADE FÍSICA SOBRE A QUALIDADE AMBIENTAL SONORA DOS PARQUES PÚBLICOS DE CURITIBA-PARANÁ}

O tempo de medição em cada ponto foi de 15 minutos, em dias com condições climáticas ausentes de chuva e vento forte. Este tempo foi determinado com base em outras pesquisas que efetuaram medições acústicas em parques urbanos (NILSSON \& BERGLUND, 2006; SZEREMETA \& ZANNIN, 2009). Optou-se também por apenas uma amostra de dados acústicos em cada parque. Assim, foram descartadas repetições, já que por observação das áreas e seu entorno, verificou-se que o fluxo de veículos (principal agente de ruídos) no horário em que foram feitas as medições se mantém constante durante os dias úteis. Para todo procedimento de medição foram seguidos o que prescreve as normas ISO 1996 e NBR 10151.

Os dados medidos foram transferidos para o programa "Evaluator" (BK7820). A partir da análise desses resultados, os níveis sonoros $\left(L_{\text {Aeq }}\right)$ obtidos foram comparados com a legislação municipal 10.625 de 2002, que estabelece $55 \mathrm{~dB}$ (A) como o nível máximo permissível no período diurno para áreas verdes (AV). Com este mesmo software foi estabelecido um valor médio dos níveis sonoros de cada parque, os quais também foram comparados com os mesmos índices anteriormente citados e associados à qualidade do ambiente sonoro percebida por seus usuários.

\subsubsection{Mapeamento acústico}

Este procedimento utilizou o software Predictor versão 6.2 da empresa Brüel \& Kjaer, que permite visualizar e interpretar a situação acústica de determinada área geográfica, concebendo a diversidade de níveis sonoros por faixas em diferentes tonalidades de cores, nos planos horizontais e/ou nos planos tridimensionais. No entanto, para a viabilização dos mapas acústicos dos parques foi primeiro necessário a elaboração de "modelos" geométricos, no Predictor, de cada área de estudo considerando as variáveis: fontes sonoras e forma urbana. Para este processo foi utilizada a base de dados digital das regiões estudadas, com representação das curvas de nível (altimetria) e ortofotocarta georreferenciada que representa a planta baixa de cada área estudada. As etapas necessárias para a elaboração dos modelos geométricos e, consequente, mapeamento acústico são descritas a seguir. 


\section{A PERCEPÇÃO DOS PRATICANTES DE ATIVIDADE FÍSICA SOBRE A QUALIDADE AMBIENTAL SONORA DOS PARQUES PÚBLICOS DE CURITIBA-PARANÁ}

Primeiramente, as áreas de estudo foram delimitadas através de fotografias de satélite (GOOGLE EARTH, 2010). Após este processo, partiu-se para a construção do modelo geométrico de cada região de estudo. As curvas de nível contidas na base de dados (IPPUC - Curitiba Digital - Edição 2006/CD-ROM) e a ortofotocarta georreferenciada do parque (IPPUC, 2006) foram diretamente importadas para o Predictor.

Em seguida, com base na ortofotocarta, que fica sobreposta às curvas de nível, os componentes da forma urbana (principais vias do entorno, edificações, vegetação, etc.) que podem influenciar no ambiente acústico foram desenhados um a um por meio de mecanismos similares ao programa AUTOCAD. Para estes componentes, o programa permite aplicar propriedades específicas, como alturas das edificações e altura média da vegetação.

Para a aplicação mais próxima da realidade destas características foi considerada a base geográfica cedida pelo IPPUC, imagens de satélite (GOOGLE EARTH, 2010) e as visitas nos locais procedidas no primeiro semestre de 2011. Nesta coleta em campo, seguiram-se como critérios: a) a altura da vegetação foi estimada em metros, por técnica de observação visual em campo, considerando-se o estrato mais denso do remanescente florestal observado e; b) para a altura das edificações do entorno imediato foi considerado como padrão: casas médias e grandes igual $(=)$ a 3 e 4 metros, respectivamente; sobrados $=6$ metros; galpões pequenos, médios e grandes $=6,10$ e 12 metros, nesta ordem e; prédios $=3$ metros para cada pavimento.

Após a aplicação destas propriedades, constituiu-se o modelo geométrico horizontal do parque em questão (plano). Baseado neste primeiro modelo, o programa também pode disponibilizar uma versão tridimensional da área. Concebido o modelo no Predictor, para a etapa final foi necessário inserir no mesmo os dados referentes às fontes de ruído, tais como: os $L_{\text {Aeq }}$ dos pontos medidos na área estudada, o fluxo por hora e a velocidade média dos veículos das vias do entorno imediato. 


\section{A PERCEPÇÃO DOS PRATICANTES DE ATIVIDADE FÍSICA SOBRE A QUALIDADE AMBIENTAL SONORA DOS PARQUES PÚBLICOS DE CURITIBA-PARANÁ}

Estas informações foram coletadas em cada parque em 2011, durante os meses de novembro e dezembro, na faixa de horário entre 17 e 19 horas. Para tanto, foram adotados os seguintes procedimentos: a) Medições acústicas $L_{\text {Aeq }}$ ) no interior da área dos parques, como descrito anteriormente; b) Contagem do fluxo de veículos de cada via do entorno imediato do parque em questão, realizada visualmente pelo autor da pesquisa, em um período de 15 minutos contabilizando separadamente veículos leves (carros), motos e pesados (ônibus e caminhões). Posteriormente multiplicou-se o número de veículos contados por quatro para a obtenção do fluxo por hora; c) Estimativa da velocidade média por meio da condução de um automóvel nestas vias circundantes, verificando-se o seu velocímetro e respeitando os limites de velocidade sinalizados. Cada percurso foi repetido por três vezes.

Após a inserção destes últimos dados no modelo, o software Predictor iniciou a etapa de cálculo para obter o mapa acústico do parque em questão. Finalizado o cálculo, o qual considerou as características das variáveis da forma urbana e fontes sonoras inseridas, foi gerado o mapa sonoro nos planos horizontais e verticais (3D) representados com faixas de gradação de cores. Neste artigo são apresentados apenas os mapas em suas configurações planas.

Para que fosse possível identificar as áreas que se encontram os equipamentos de ginástica e lazer, os mapas acústicos foram trabalhados no programa Paint. Neste software foi possível delimitar estas áreas por meio de desenhos de circunferências com margens em preto, uma vez que o Predictor não apresenta esta característica.

Os mapas acústicos tem se mostrado muito úteis, para se avaliar o ruído no meio ambiente urbano (KING \& RICE, 2009; PINTO \& MARDONES, 2009; ZANNIN \& SANT'ANA, 2011; GUEDES et al, 2011; CASAS et al, 2014). 


\section{A PERCEPÇÃO DOS PRATICANTES DE ATIVIDADE FÍSICA SOBRE A QUALIDADE AMBIENTAL SONORA DOS PARQUES PÚBLICOS DE CURITIBA-PARANÁ}

\subsubsection{Entrevistas}

\subsubsection{População e amostra}

A população deste estudo foi constituída por residentes adultos do município de Curitiba-Paraná que usualmente frequentam os parques urbanos selecionados para praticar atividade física. Foram entrevistadas pessoas com idade a partir de 18 anos e que estavam no interior do parque. As entrevistas foram realizadas pelos autores do presente estudo.

Estas foram procedidas, em cada parque, em dias úteis da semana, no mesmo período do dia (17 às 19 horas) em que foi realizado o procedimento de mensurações acústicas, de forma a manter maior consistência para a associação dos seus dados com os dados acústicos na análise dos resultados. Em média a coleta foi realizada em dez dias em cada parque, num período total de três meses (março a maio de 2012), totalizando 82 entrevistas por área.

Um termo de consentimento foi usado como um informativo sobre a pesquisa e para a autorização do entrevistado. A pesquisa foi aprovada no Comitê de Ética em Pesquisa do Setor de Ciências da Saúde da Universidade Federal do Paraná $\left(\mathrm{N}^{0}\right.$ 12842091112).

\subsubsection{Questionário}

O questionário utilizado para o presente estudo foi elaborado pelo autor deste estudo com base em questões do instrumento original (validado) de Nilsson e Berglund (2006). Apresenta questões em escala de múltipla escolha, ordinais (likert) e nominais, das quais algumas foram categorizadas e/ou dicotomizadas para análise. Este instrumento abrange aspectos sobre a percepção ambiental dos usuários no parque e alguns fatores individuais dos mesmos, tais como: a percepção da qualidade do ambiente, com foco principal na qualidade da paisagem sonora; nível de incômodo ao ruído e a outros fatores sociais e ambientais; frequência de identificação de sons; expectativas em relação aos sons ouvidos; sensibilidade ao ruído, saúde auditiva, gênero, idade e perfil de uso do parque (tempo de permanência e frequência). Para elaboração desta parte foram utilizadas doze 


\section{A PERCEPÇÃO DOS PRATICANTES DE ATIVIDADE FÍSICA SOBRE A QUALIDADE AMBIENTAL SONORA DOS PARQUES PÚBLICOS DE CURITIBA-PARANÁ}

questões de um total de dezenove do questionário de Nilsson e Berglund (2006) que investigaram a paisagem sonora de parques urbanos e áreas suburbanas na Suécia. As demais perguntas não foram aproveitadas por não serem direcionadas à percepção do ambiente sonoro e, especificamente, não adequadas ao público que desenvolve atividade física em parques urbanos. $O$ instrumento com versão na língua inglesa foi cedido por contato de e-mail com os autores. As questões selecionadas foram traduzidas pelo método de "tradução reversa", que consiste em tradução inicial, análises por comitê de especialistas, "tradução reversa" e adaptação cultural (FLECK, 1999).

\subsubsection{Análise de dados}

Os dados das entrevistas foram tabulados no programa Excel 2007 e para a elaboração dos relatórios estatísticos foi utilizado o programa SPSS versão 14.0 (Statistical Package for the Social Sciences). Neste mesmo software foi verificada a consistência interna do questionário por meio do coeficiente Alpha de Cronbach, o qual foi satisfatório $(\alpha=0.785)$. Na descrição da amostra foi aplicada a estatística descritiva, com a apresentação de frequências absolutas e relativas (\%) dos dados e em alguns casos a média. Para verificar se ocorreram diferenças estatísticas significativas entre a área controle (Bacacheri) e as amostras dos demais parques foi utilizado o teste do qui-quadrado $\left(\mathrm{X}^{2}\right)$ com um nível de significância de $5 \%$.

\section{RESULTADOS E DISCUSSÕES}

\subsection{Dados acústicos}

$\mathrm{Na}$ Tabela 2 são apresentados o número de pontos medidos e os resultados das mensurações acústicas $\left(L_{\text {Aeq }}\right)$ em cada parque. 


\section{A PERCEPÇÃO DOS PRATICANTES DE ATIVIDADE FÍSICA SOBRE A QUALIDADE AMBIENTAL SONORA DOS PARQUES PÚBLICOS DE CURITIBA-PARANÁ}

Tabela 2: Número de pontos e resultados das medições acústicas em cada parque

\begin{tabular}{ccccc}
\hline Parque Urbano & $\begin{array}{c}\text { Número de } \\
\text { Pontos } \\
\text { Medidos }\end{array}$ & Variação de $\mathrm{L}_{\text {Aeq }}$ & $\begin{array}{c}\text { Número de pontos } \\
\text { acima do permitido } \\
\text { (Lei 10625) }\end{array}$ & L $_{\text {Aeq }}$ dB (Média) \\
\hline Passeio Público & 6 & 59 a 67 & 6 & 64 \\
Jardim Botânico & 9 & 54 a 72 & 7 & 67 \\
São Lourenço & 7 & 53 a 65 & 4 & 60 \\
Bacacheri (grupo controle) & 7 & 52 a 58 & 2 & 55 \\
\hline
\end{tabular}

Considerando os valores médios, apenas o parque Bacacheri (área controle) está de acordo com a legislação local que estabelece o limite de $55 \mathrm{~dB}(\mathrm{~A})$ para áreas verdes no período diurno. Assim, os demais parques estudados se apresentam acusticamente poluídos, com a maioria dos pontos mensurados acima do permitido pela lei 10.625 de Curitiba.

A seguir são apresentados os mapas acústicos de cada parque com a identificação das áreas (delimitadas por circunferências) que se encontram os equipamentos de ginástica e lazer. 


\section{A PERCEPÇÃO DOS PRATICANTES DE ATIVIDADE FÍSICA SOBRE A QUALIDADE AMBIENTAL SONORA DOS PARQUES PÚBLICOS DE CURITIBA-PARANÁ}

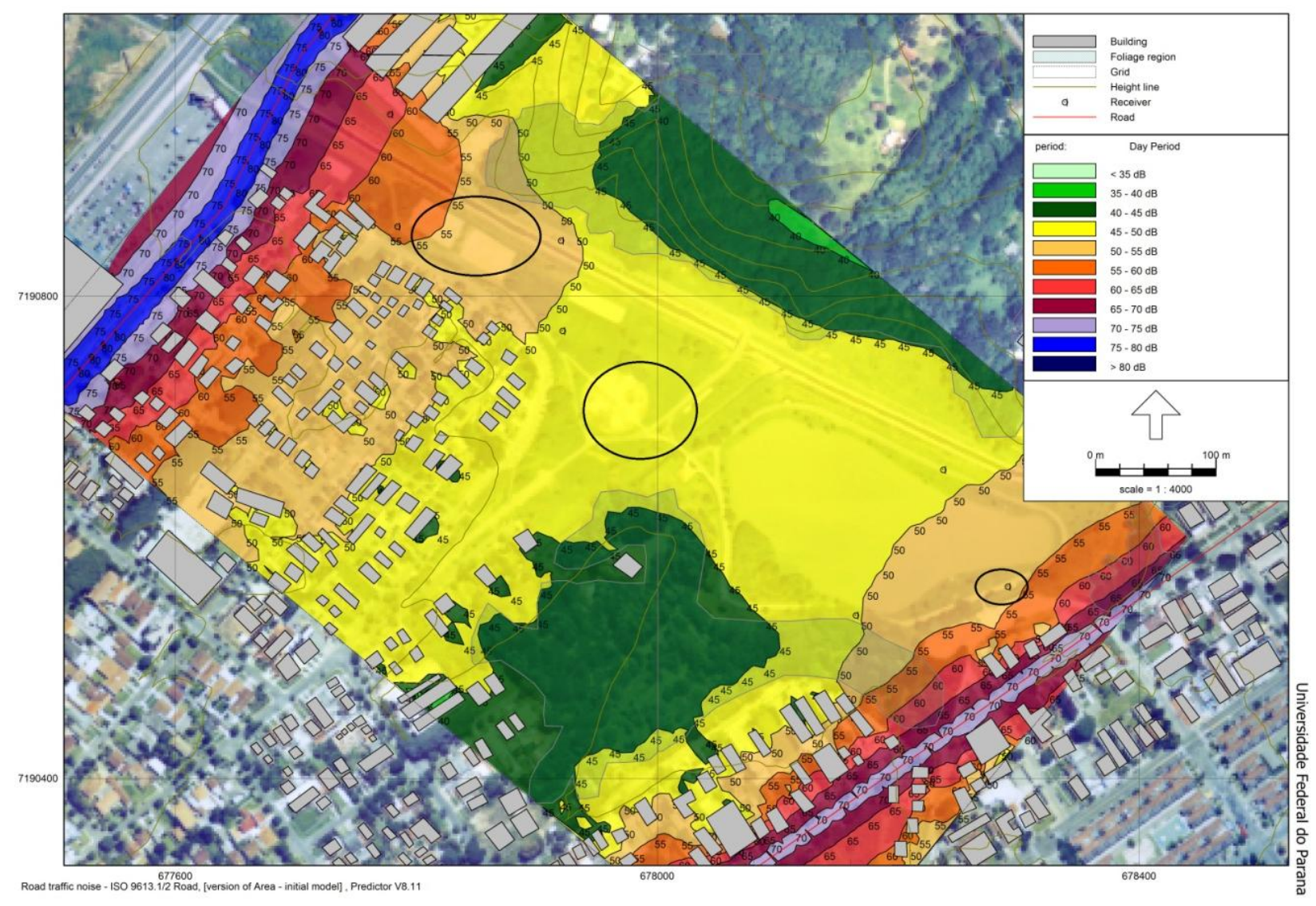

Figura 2: Mapa acústico do Parque Bacacheri.

Como demonstrado na Figura 2, uma maior região do parque Bacacheri apresenta níveis sonoros ente 45 e $55 \mathrm{~dB}(\mathrm{~A})$. Dentre os três espaços que o parque possui com equipamentos de ginástica e lazer, somente parte de uma destas áreas esta exposta a níveis superiores de ruído ambiental (entre $55 \mathrm{db}[\mathrm{A}]$ e $60 \mathrm{~dB}[\mathrm{~A}]$ ), de acordo com a legislação da cidade de Curitiba. Isto se deve que, diferentemente dos demais parques estudados, apenas uma pequena parte de sua extensão faz fronteira e está mais próxima a vias de intenso tráfego de veículos automotores. Pois, o parque se encontra em uma posição perpendicular as duas avenidas, que são as principais fontes de ruído, sendo limitado principalmente por outras áreas verdes e conjuntos residenciais com ruas pouco movimentadas, com a circulação de veículos de apenas moradores e de visitantes do próprio parque. 


\section{A PERCEPÇÃO DOS PRATICANTES DE ATIVIDADE FÍSICA SOBRE A QUALIDADE AMBIENTAL SONORA DOS PARQUES PÚBLICOS DE CURITIBA-PARANÁ}

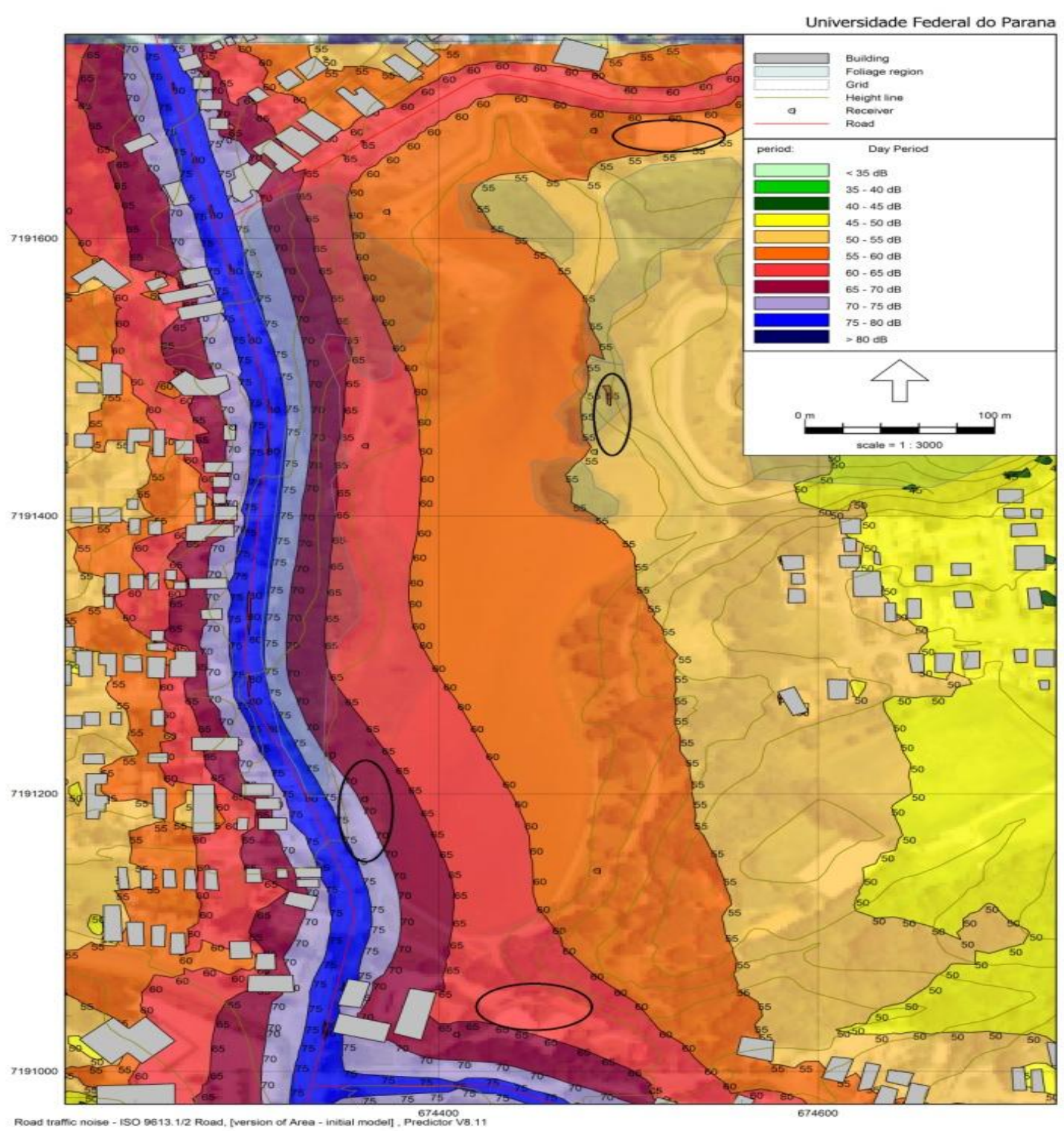

Figura 3: Mapa acústico do Parque São Lourenço.

A maior parte do perímetro do parque (Figura 3) São Lourenço esta situada paralelamente a uma grande avenida (ao oeste) com elevado tráfego viário. Ao sul, o parque também faz fronteira com outra rua com elevada circulação de veículos. Assim o São Lourenço apresenta, na maior porção de sua área útil, níveis sonoros elevados que variam entre 55 e $70 \mathrm{~dB}(\mathrm{~A})$. Apenas uma dentre as quatro estruturas 


\section{A PERCEPÇÃO DOS PRATICANTES DE ATIVIDADE FÍSICA SOBRE A QUALIDADE AMBIENTAL SONORA DOS PARQUES PÚBLICOS DE CURITIBA-PARANÁ}

de lazer e atividade física, do espaço público, se encontra em área com níveis aceitáveis de ruído ambiental (entre $50 \mathrm{~dB}[\mathrm{~A}]$ e $55 \mathrm{~dB}[\mathrm{~A}]$ ).

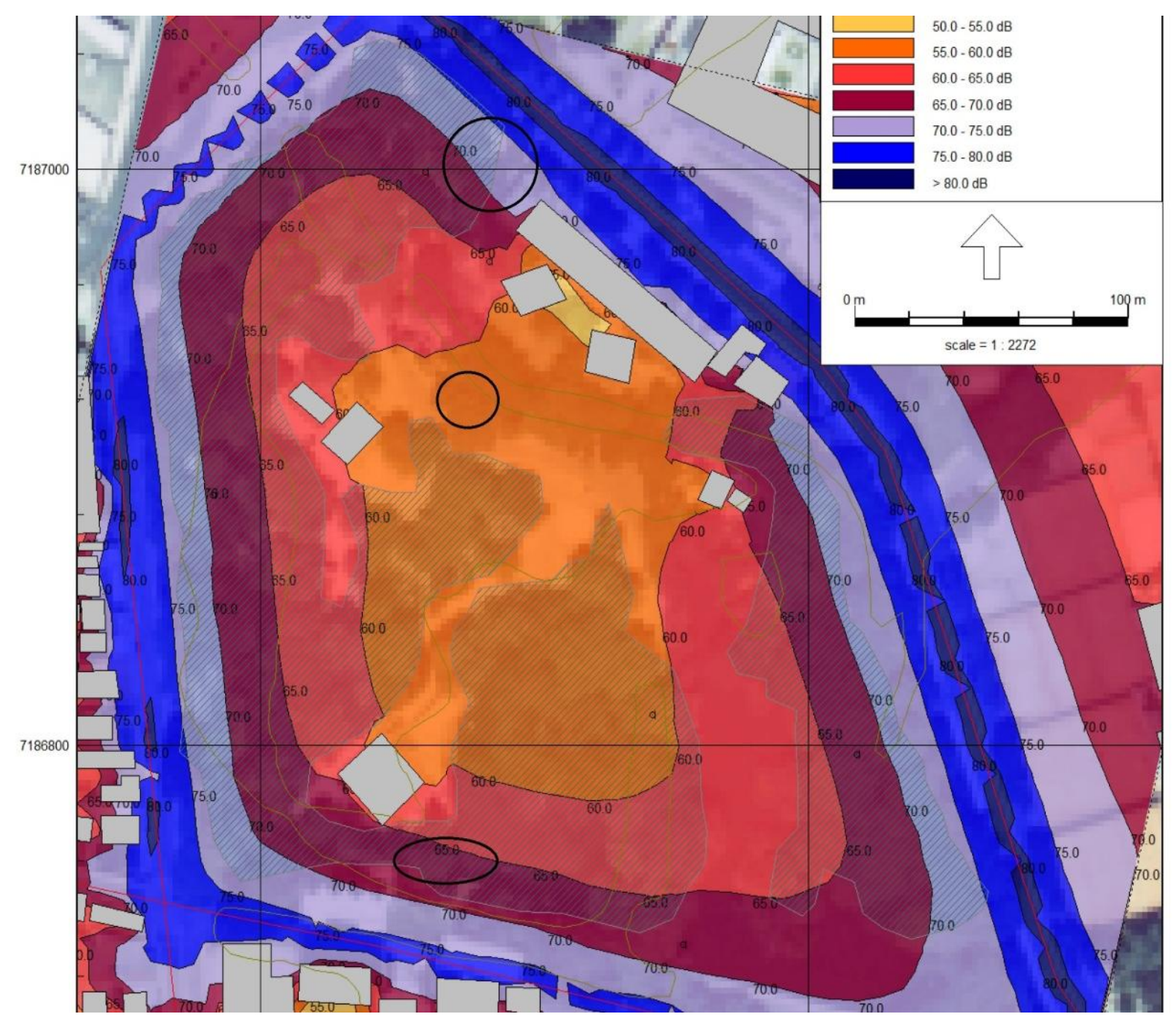

Figura 4: Mapa acústico do Parque Passeio Público.

O parque Passeio Público se localiza completamente ladeado por três vias de intenso tráfego de veículos, no Centro da cidade de Curitiba. A maior parte da sua área útil é representada, no mapeamento acústico (Figura 4) por níveis sonoros superiores em relação ao limite imposto pela legislação municipal 10625, entre 60 e $70 \mathrm{~dB}(\mathrm{~A})$. Deste modo, todas as três áreas com estruturas de lazer e atividade física ficam expostas a elevados níveis de ruído ambiental, emitidos do entorno imediato. 


\section{A PERCEPÇÃO DOS PRATICANTES DE ATIVIDADE FÍSICA SOBRE A QUALIDADE AMBIENTAL SONORA DOS PARQUES PÚBLICOS DE CURITIBA-PARANÁ}

O Jardim Botânico também está totalmente cercado por vias de elevado fluxo de veículos (Figura 5), sendo limitado por zonas residenciais mistas (ZR-4), especiais e de transição da BR 116. Em razão disto, a sua maior região apresenta níveis sonoros elevados, entre 60 e $70 \mathrm{~dB}(\mathrm{~A})$. Todos os equipamentos de ginástica e lazer estão muito próximos das vias do entorno, onde alguns se localizam em pontos que chegam aos $70 \mathrm{~dB}(\mathrm{~A}), 15$ decibéis acima do permitido pela lei municipal 10625 .

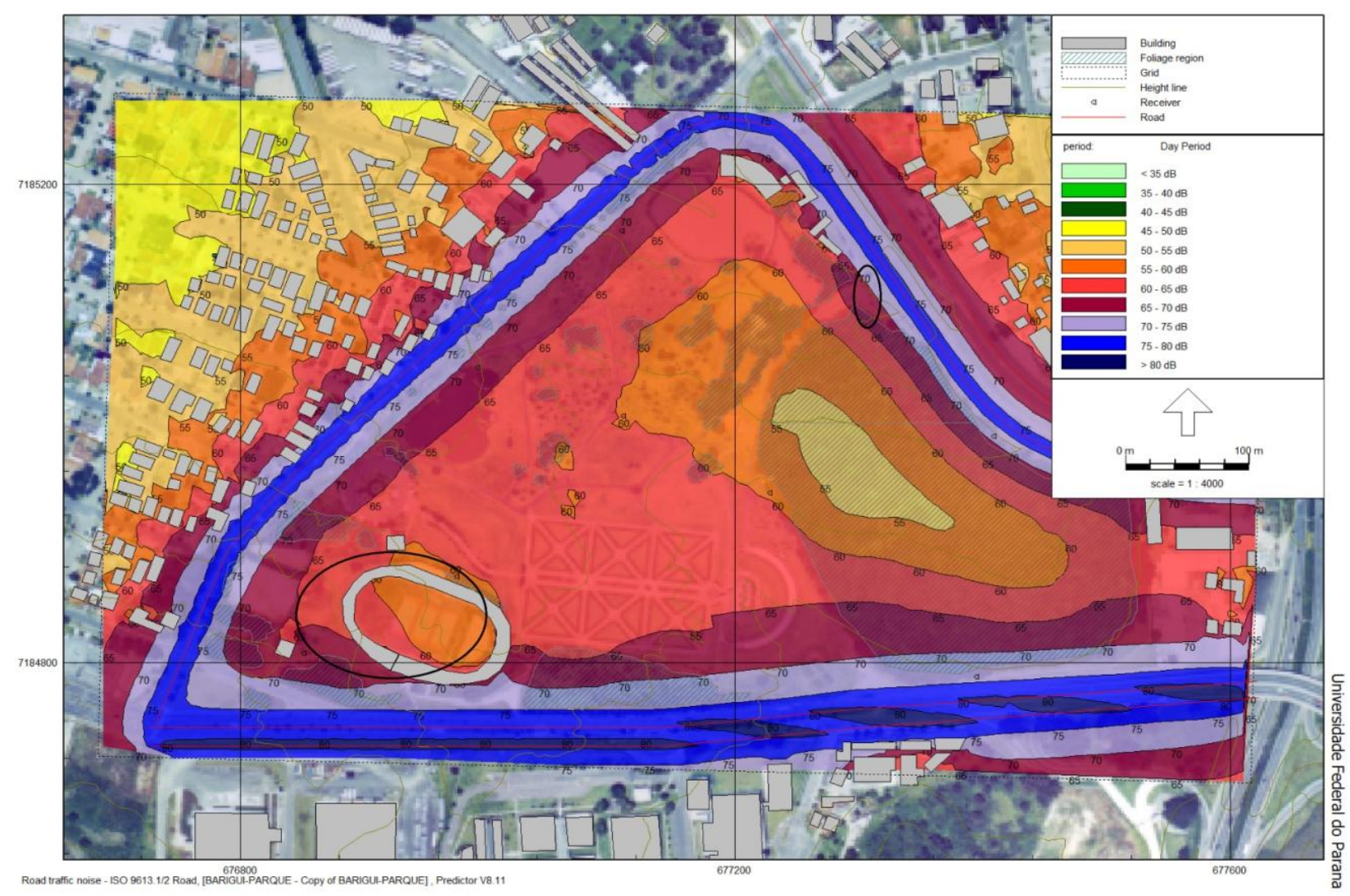

Figura 5: Mapa acústico do Parque Jardim Botânico.

Diante dos resultados das mensurações e mapas acústicos dos espaços estudados, parece que não há um planejamento que vise um melhor conforto ambiental dos usuários, principalmente dos praticantes de atividade física. Uma vez que, as áreas onde estão os equipamentos de treinamento físico e as "academias ao ar livre", principalmente nos parques acusticamente poluídos, estão situadas em 


\section{A PERCEPÇÃO DOS PRATICANTES DE ATIVIDADE FÍSICA SOBRE A QUALIDADE AMBIENTAL SONORA DOS PARQUES PÚBLICOS DE CURITIBA-PARANÁ}

regiões mais próximas das vias de intenso fluxo de veículos, fontes lineares de ruído e também responsáveis por emissões de gases tóxicos. Portanto, esta situação não deve ser admitida porque pode promover uma percepção negativa do ambiente, deixando-o menos atrativo para o uso (COHEN, 2007; CASSOU, 2009; COHEN, 2010), assim como, prejudicar os benefícios psicológicos, até mesmo imediatos, que o contato com estes espaços públicos podem estabelecer (PAYNE, 2008; IRVINE et al, 2009; BARTON \& PRETTY, 2010).

As pistas de caminhada também estão muito próximas destas vias. No entanto, compreende-se a lógica de não alocá-las em áreas mais afastadas do perímetro porque diminuiriam em extensão, podendo ficar menos atrativas aos usuários. Neste caso, propõe-se que em parques que foram ou serão implantados em áreas ainda pouco urbanizadas, seja aplicada uma política eficiente, visando determinar nas proximidades do parque (entorno) uma "zona de amortecimento sonoro", na qual teriam que ser obedecidos critérios mais rígidos para o uso do solo. Ou seja, adequar próximos a estas áreas outras consideradas também sensíveis à poluição sonora, assim como proporcionar um desenho urbano que seja compatível com as funções e uso dos parques, com áreas mais abertas e arborizadas (SZEREMETA \& ZANNIN, 2009).

\subsection{Entrevistas}

\subsubsection{Perfil da amostra}

Foram entrevistadas 82 pessoas em cada parque, totalizando 328 sujeitos participantes do estudo. A tabela 3 apresenta o número de entrevistas realizadas, dados de identificação dos entrevistados e suas formas de utilização dos parques. 


\section{A PERCEPÇÃO DOS PRATICANTES DE ATIVIDADE FÍSICA SOBRE A QUALIDADE AMBIENTAL SONORA DOS PARQUES PÚBLICOS DE CURITIBA-PARANÁ}

Tabela 3: Perfil dos usuários

\begin{tabular}{lcc}
\hline & Total & Percentual (\%) \\
\hline Masculino & Gênero & 50.3 \\
Feminino & 165 & 49.7 \\
& 163 & \\
18 a 29 anos & Idade & 38.7 \\
30 a 39 anos & 127 & 19.2 \\
40 a 49 anos & 63 & 14 \\
50 anos ou mais & 46 & 28.1 \\
& 92 & 3.6 \\
Fundamental & Nível de Instrução & 27.4 \\
Médio & 12 & 68.9 \\
Superior & 90 & \\
& 226 & 39.9 \\
Menos que 1 hora & Tempo de permanência no parque & 47.3 \\
1 hora a 2 horas & 131 & 12.8 \\
Mais que 2 horas & 155 & 79 \\
Habituais ( $\geq 1$ vez) & 42 & 21 \\
Ocasionais $(<1$ vez) & Frequência de utilização do parque na semana \\
\hline
\end{tabular}

\subsubsection{Percepção Sonora e Ambiental}

Qualidade do ambiente em geral

Observa-se na Figura 6 que, em todos os parques, a maioria dos usuários avaliou positivamente a qualidade do ambiente num contexto geral. No total, apenas 9\% da amostra julgou o ambiente de forma negativa ("ruim" e/ou "muito ruim"). No entanto, não se deve descartar a possibilidade destes usuários estarem acostumados ou adaptados ao ambiente, uma vez que a maioria se trata de frequentadores habituais. Além disso, a comparação do parque com outros locais do cotidiano destas pessoas, como o local que trabalham e/ou onde residem, pode têlos induzido a uma melhor avaliação da qualidade do ambiente (ZANNIN \& SZEREMETA, 2003). 


\section{A PERCEPÇÃO DOS PRATICANTES DE ATIVIDADE FÍSICA SOBRE A QUALIDADE AMBIENTAL SONORA DOS PARQUES PÚBLICOS DE CURITIBA-PARANÁ}

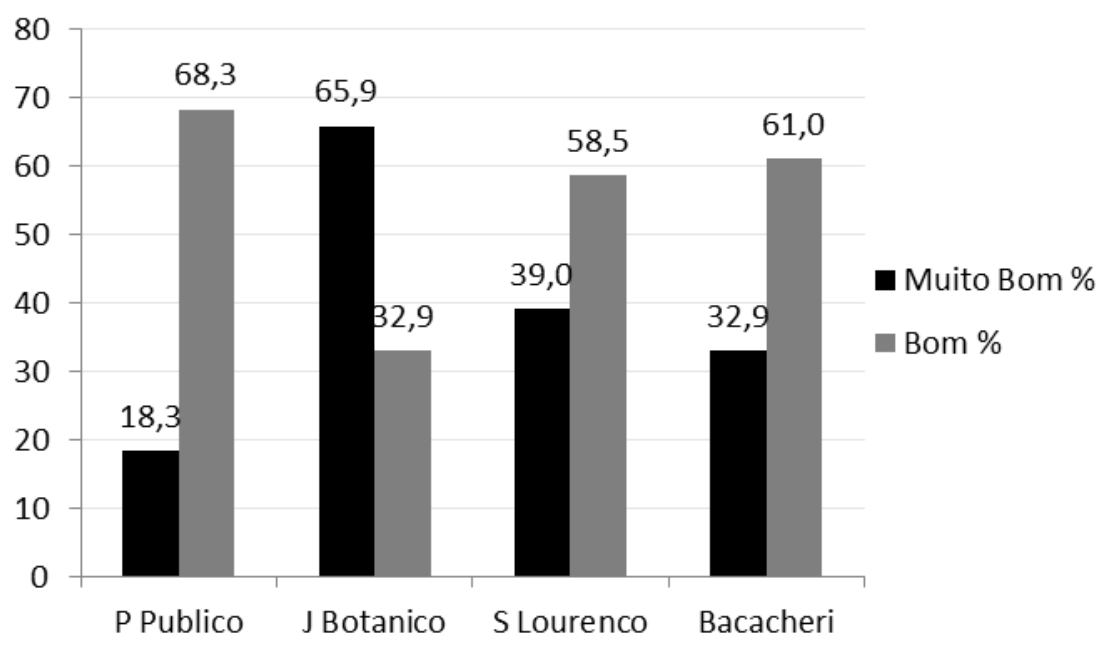

Figura 6: Percentual da avaliação positiva do ambiente.

Sensibilidade ao ruído

A Tabela 4 mostra o perfil dos usuários referentes à saúde auditiva e a sensibilidade ao ruído. Em média, em todos os parques, os usuários admitiram ser "parcialmente sensíveis" ao ruído. Uma vez que os valores 3 a 3,4 correspondem a este nível da variável na escala de sensibilidade auditiva. No total, apenas 17 (5,2\%) dos 328 entrevistados afirmaram ter problemas de audição. Destes apenas três declararam usar aparelho auditivo.

Tabela 4: Características auditivas dos entrevistados

\begin{tabular}{ccccccc}
\hline & Passeio Público & Jardim Botânico & São Lourenço & Bacacheri & Total \\
\hline Problemas de Audição \% & 7,3 & 2,4 & 4,9 & 6,1 & 5,2 \\
Média: Sensibilidade ao ruído & 3 & 3,3 & 3,1 & 3,4 & 3,2 \\
\hline
\end{tabular}

Expectativas e comparação em relação ao ambiente sonoro

$\mathrm{Na}$ Tabela 5 observam-se as proporções de sujeitos que "concordaram" que os sons presentes no parque estavam de acordo com o que esperavam, assim como dos que admitiram que a paisagem sonora do parque combinava com a paisagem visual. O Jardim Botânico e o Bacacheri (área controle) apresentam os maiores percentuais de entrevistados com estas duas características, porém com diferenças 


\section{A PERCEPÇÃO DOS PRATICANTES DE ATIVIDADE FÍSICA SOBRE A QUALIDADE AMBIENTAL SONORA DOS PARQUES PÚBLICOS DE CURITIBA-PARANÁ}

significativas entre os mesmos para o comparativo da paisagem visual com a paisagem sonora $(p=0.049)$.

Tabela 5 - Expectativas e comparativo da paisagem sonora

\begin{tabular}{|c|c|c|c|c|c|c|c|c|c|c|c|c|c|}
\hline & \multicolumn{3}{|c|}{ P Público } & \multicolumn{3}{|c|}{ J Botânico } & \multicolumn{3}{|c|}{ S Lourenço } & \multicolumn{2}{|c|}{ Bacacheri } & \multicolumn{2}{|c|}{ Total } \\
\hline & $\mathrm{Fa}$ & $\%$ & $p$ & & $\%$ & $p$ & $\mathrm{Fa}$ & $\%$ & $p$ & $\mathrm{Fa}$ & $\%$ & $\mathrm{Fa}$ & $\%$ \\
\hline $\begin{array}{c}\text { Expectativa } \\
\text { aos sons }\end{array}$ & 54 & 65.9 & ${ }^{*} 0.000$ & 67 & 81.7 & 0.185 & 56 & 68.3 & ${ }^{*} 0.001$ & 73 & 89.0 & 250 & 76.2 \\
\hline $\begin{array}{c}\text { Paisagem } \\
\text { visual combina }\end{array}$ & 35 & 42.7 & ${ }^{*} 0.000$ & 61 & 74.4 & ${ }^{*} 0.049$ & 46 & 56,1 & ${ }^{*} 0.000$ & 71 & 86.6 & 213 & 64.9 \\
\hline
\end{tabular}

Nos outros dois parques, ambos com diferenças significativas em relação à área controle, verifica-se uma mais baixa proporção de usuários que concordaram que os sons ouvidos no parque correspondiam as suas expectativas e que 0 ambiente sonoro combinava com a paisagem visual.

Vale lembrar que a "beleza do local" (65,5\%), depois da distância de casa, foi o principal motivo para frequentar os parques, pois a paisagem visual é uma das principais qualidades positivas destas áreas. Assim, presume-se que quando a paisagem sonora está em acordo com a paisagem visual pode colaborar para uma melhor qualidade do ambiente acústico na percepção dos sujeitos. Neste sentido, de acordo com os resultados, os parques Bacacheri e Jardim Botânico podem apresentar uma melhor qualidade ambiental em relação aos demais parques. Ainda, independente dos tipos de sons identificados e de sua semântica e níveis de pressão sonora (agradável ou desagradável), nestes dois parques, os eventos sonoros correspondem às expectativas dos usuários, o que também deve permitir uma melhor avaliação na escala da qualidade do ambiente sonoro (NILSSON \& BERGLUND, 2006).

Identificação de sons

Os entrevistados foram questionados sobre com que frequência ouviram determinados sons durante a visita no parque, considerando-se três grupos de fontes sonoras: sons humanos, sons da natureza e sons mecânicos. A tabela 6 


\section{A PERCEPÇÃO DOS PRATICANTES DE ATIVIDADE FÍSICA SOBRE A QUALIDADE AMBIENTAL SONORA DOS PARQUES PÚBLICOS DE CURITIBA-PARANÁ}

apresenta somente as proporções de usuários que admitiram ouvir "frequentemente" sons provindos destas fontes.

Tabela 6: Número e percentual de usuários que ouviram "Frequentemente" sons das três fontes sonoras

\begin{tabular}{lccccccccccccccc}
\hline & \multicolumn{1}{c}{ Passeio Público } & \multicolumn{3}{c}{ Jardim Botânico } & \multicolumn{3}{c}{ São Lourenço } & \multicolumn{3}{c}{ Bacacheri } & \multicolumn{2}{c}{ Total } \\
\hline & Fa & $\%$ & $\mathrm{p}$ & $\mathrm{Fa}$ & $\%$ & $\mathrm{p}$ & $\mathrm{Fa}$ & $\%$ & $\mathrm{p}$ & $\mathrm{Fa}$ & $\%$ & $\mathrm{Fa}$ & $\%$ \\
Sons Natureza & 45 & 54.9 & 0.122 & 52 & 63.4 & 0.986 & 44 & 53.7 & 0.255 & 53 & 64.6 & 194 & 59.1 \\
Sons Humanos & 26 & 31.7 & ${ }^{*} 0.000$ & 24 & 29.3 & ${ }^{*} 0.000$ & 36 & 43.9 & ${ }^{*} 0.002$ & 56 & 68.3 & 142 & 43.3 \\
Sons Mecânicos & 61 & 74.4 & ${ }^{*} 0.000$ & 52 & 63.4 & ${ }^{*} 0.000$ & 54 & 65.9 & ${ }^{*} 0.000$ & 18 & 22 & 185 & 56.4 \\
\hline${ }^{*} \mathrm{p}<0.05\left(\mathrm{X}^{2}\right)$ & & & & & & & & & & & & & & &
\end{tabular}

Nos parques Passeio Público (74,4\%), Jardim Botânico (63,4\%) e São Lourenço $(65,9 \%)$, os sons mecânicos ou tecnológicos foram ouvidos com frequência pela maioria dos entrevistados. Estas três áreas apresentam diferença estatística significativa em comparação ao parque Bacacheri (área controle), no qual apenas $22 \%$ dos usuários identificaram estes tipos de sons com frequência. Estes resultados mostram que a proximidade de parques urbanos com vias de intenso tráfego do entorno facilita a percepção do ruído de trânsito, uma vez que o Bacacheri (área controle) é a única área do estudo que se encontra mais afastada destas fontes de ruído.

Já os sons da natureza foram identificados com frequência, pela maioria dos sujeitos, nos quatro parques. Neste caso não foram constatadas diferenças significativas em relação à área controle. Estes resultados são atribuídos em função da tipologia destas áreas, que apresentam abundantes vegetações e lagos que conservam elementos naturais da flora e fauna nativas que, consequentemente, colaboram com a composição da paisagem sonora destes espaços (IRVINE et al, 2009; SZEREMETA \& ZANNIN, 2009). Assim, é muito comum ouvir, principalmente, sons de aves e do contato do vento com a vegetação. Portanto, mesmo nos parques que se encontram em regiões de saturação urbana, com intensos níveis de ruído, os sons da natureza não foram mascarados por sons mecânicos. 


\section{A PERCEPÇÃO DOS PRATICANTES DE ATIVIDADE FÍSICA SOBRE A QUALIDADE AMBIENTAL SONORA DOS PARQUES PÚBLICOS DE CURITIBA-PARANÁ}

Esta realidade é positiva, pois os sons da natureza são comumente julgados como agradáveis por uma população (SCHAFER, 2001; PEREIRA, 2003; SZEREMETA \& ZANNIN, 2009). Deste modo, a percepção destes eventos sonoros pode melhorar a impressão que o sujeito tem do ambiente sonoro, mesmo em áreas com a presença de ruído de trânsito, os quais são geralmente considerados como sons desagradáveis (YANG \& KANG, 2005a; NILSSON \& BERGLUND, 2006; SZEREMETA \& ZANNIN, 2009; JEON et al, 2010).

Em relação aos sons humanos apenas no Bacacheri a maioria dos usuários os ouviu de forma frequente $(68,3 \%)$. No São Lourenço, Passeio público, Jardim Botânico, somente $43,9 \%, 31,7 \%$ e $29,3 \%$, dos sujeitos, respectivamente, admitiram ouvir com frequência estes sons. Assim, percebe-se que os sons humanos foram menos ouvidos nos parques em que os sons mecânicos foram identificados com frequência pela maioria dos usuários. Deste modo, parece que os sons mecânicos conseguem mascarar os sons de fontes humanas (vozes, passos, etc.) prejudicando a inteligibilidade nestas áreas verdes. Ou seja, estes sons não são identificados com plena distinção. Estes dados são preocupantes porque os sons humanos são geralmente classificados pelas comunidades como agradáveis ou "neutros" (YANG \& KANG, 2005a; SZEREMETA \& ZANNIN, 2009) e como os sons da natureza podem proporcionar uma melhor qualidade do ambiente sonoro. Além disso, são importantes para fatores ligados a comunicação e sociabilidade.

Estes resultados demonstram que a paisagem sonora dos parques é caracterizada principalmente por sons da natureza e sons mecânicos. Este fato mostra a necessidade de projetos que visem a conservação dos sons naturais e o controle dos sons mecânicos. Pois estes últimos são comumente considerados desagradáveis pelos cidadãos (SZEREMETA \& ZANNIN, 2009), podendo trazer incômodo aos mesmos e, dependendo de sua intensidade sonora (volume), podem mascarar os sons de significado agradável. 


\section{A PERCEPÇÃO DOS PRATICANTES DE ATIVIDADE FÍSICA SOBRE A QUALIDADE AMBIENTAL \\ SONORA DOS PARQUES PÚBLICOS DE CURITIBA-PARANÁ}

Incômodo ao ruído

Na Figura 7 são mostrados os fatores sociais e ambientais que incomodaram de alguma forma os usuários dos parques. Neste os níveis de incômodo investigados (extremamente, muito, moderadamente e, um pouco) foram agrupados em apenas uma categoria denominada "incomoda".

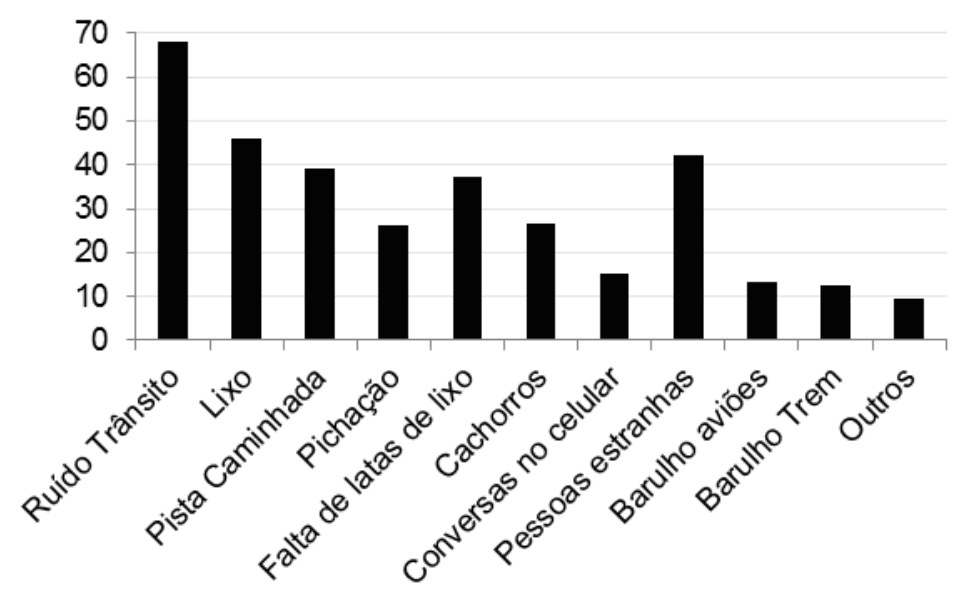

Figura 7: Fatores de incômodo nos parques (\%).

Observa-se que o ruído de tráfego rodoviário é o fator sócio ambiental que mais incomoda nos parques (68\%). Logo em seguida, a presença de "lixo" e de "pessoas estranhas" também apresentam percentuais consideráveis (acima de 40\%) de entrevistados incomodados.

Na Tabela 7 são apresentados os níveis de incômodo dos sujeitos, de cada parque, em relação ao ruído de trânsito. Na área controle (Bacacheri), como esperado, a maioria dos usuários não se incomodou com o ruído de tráfego rodoviário (64,6\%). Nas demais áreas, as quais apresentaram valores médios de $L_{\text {Aeq }}$ elevados e identificação frequente de sons mecânicos, entre $74,4 \%$ e $85,4 \%$ se incomodaram de algum modo com este agente. Nestas, a maioria admitiu se incomodar moderadamente $(30,5 \%$ a $36,6 \%)$.

O Passeio Público se destaca por ser o parque que apresenta as maiores proporções de sujeitos que se incomodaram muito e extremamente com este tipo de ruído, perfazendo juntos 39\%. Assim todos os parques apresentam diferenças estatísticas significativas para o "incômodo ao ruído" em relação ao Bacacheri. Estas 


\section{A PERCEPÇÃO DOS PRATICANTES DE ATIVIDADE FÍSICA SOBRE A QUALIDADE AMBIENTAL SONORA DOS PARQUES PÚBLICOS DE CURITIBA-PARANÁ}

evidências demonstram que este tipo de perturbação está relacionado ao contexto urbano destes parques que possibilita uma maior aproximação das fontes de ruído. Pois na área controle os sons mecânicos foram raramente identificados e o valor médio de $L_{A E q}(55 \mathrm{~dB})$ foi o menos elevado.

Tabela 7: Níveis de incômodo dos entrevistados em relação ao ruído de trânsito rodoviário

\begin{tabular}{|c|c|c|c|c|c|c|c|c|c|c|c|c|c|}
\hline Incômodo & \multicolumn{3}{|c|}{ Passeio Público } & \multicolumn{3}{|c|}{ Jardim Botânico } & \multicolumn{3}{|c|}{ São Lourenço } & \multicolumn{2}{|c|}{ Bacacheri } & \multicolumn{2}{|c|}{ Total } \\
\hline & $\mathrm{Fa}$ & $\%$ & $p$ & $\mathrm{Fa}$ & $\%$ & $p$ & $\mathrm{Fa}$ & $\%$ & $p$ & $\mathrm{Fa}$ & $\%$ & $\mathrm{Fa}$ & $\%$ \\
\hline $\begin{array}{l}\text { Extremamente } \\
\text { Incomodado }\end{array}$ & 17 & 20.7 & ${ }^{*} 0.000$ & 1 & 1.2 & ${ }^{*} 0.000$ & 3 & 3.7 & ${ }^{*} 0.000$ & 3 & 3.7 & 24 & 7.3 \\
\hline $\begin{array}{c}\text { Muito } \\
\text { Incomodado }\end{array}$ & 15 & 18.3 & & 12 & 14.6 & & 10 & 12.2 & & 1 & 1.2 & 38 & 11.6 \\
\hline $\begin{array}{l}\text { Moderadamente } \\
\text { Incomodado }\end{array}$ & 25 & 30.5 & & 30 & 36.6 & & 25 & 30.5 & & 12 & 14.6 & 92 & 28.0 \\
\hline $\begin{array}{l}\text { Um Pouco } \\
\text { Incomodado }\end{array}$ & 13 & 15.9 & & 20 & 24.4 & & 23 & 28.0 & & 13 & 15.9 & 69 & 21.0 \\
\hline $\begin{array}{c}\text { Não } \\
\text { incomodado }\end{array}$ & 12 & 14.6 & & 19 & 23.2 & & 21 & 25.6 & & 53 & 64.6 & 105 & 32.0 \\
\hline Total & 82 & 100.0 & & 82 & 100.0 & & 82 & 100.0 & & 82 & 100.0 & 328 & 100.0 \\
\hline
\end{tabular}

Deste modo, é relevante se preocupar com o ruído ambiental do tráfego viário. Visto como, este incômodo pode resultar em uma percepção negativa do ambiente e, por consequência, prejudicar a frequência de utilização destes locais para a atividade física e o lazer (COLLET, 2008; CASSOU, 2009; COHEN, 2007), assim como interferir nas experiências de bem estar psicológico que estes lugares podem proporcionar durante a visita (PAYNE, 2008; IRVINE et al, 2009; BARTON \& PRETTY, 2010).

Qualidade Ambiental Sonora

Para avaliar a qualidade do ambiente sonoro nas áreas pesquisadas foi utilizado o mesmo critério de Nilsson e Berglund (2006). Este parâmetro considera que um parque tem "boa qualidade" apenas quando $80 \%$ ou mais de seus usuários a classificarem desta forma na escala de qualidade do ambiente sonoro (opções: "boa" e/ou "muito boa"). 


\section{A PERCEPÇÃO DOS PRATICANTES DE ATIVIDADE FÍSICA SOBRE A QUALIDADE AMBIENTAL SONORA DOS PARQUES PÚBLICOS DE CURITIBA-PARANÁ}

As informações referentes a esta questão são demonstradas na Tabela 8. Observa-se que, de acordo com o critério adotado, apenas o parque Bacacheri apresenta uma boa qualidade do ambiente sonoro, no qual $89 \%$ dos sujeitos o avaliaram positivamente. Nos parques Passeio Público, São Lourenço e Jardim Botânico, apenas 32\%, 60\% e 66\% dos entrevistados, respectivamente, perceberam o ambiente sonoro de forma positiva. Assim, todas estas áreas apresentam diferença significativa em relação à área controle na escala de avaliação do ambiente sonoro.

Tabela 8: Distribuição de frequências da escala de qualidade do ambiente sonoro

\begin{tabular}{|c|c|c|c|c|c|c|c|c|c|c|c|c|c|}
\hline & \multicolumn{3}{|c|}{ Passeio Público } & \multicolumn{3}{|c|}{ Jardim Botânico } & \multicolumn{3}{|c|}{ São Lourenço } & \multicolumn{2}{|c|}{ Bacacheri } & \multicolumn{2}{|c|}{ Total } \\
\hline Ambiente Sonoro & $\mathrm{Fa}$ & $\%$ & $p$ & $\mathrm{Fa}$ & $\%$ & $p$ & $\mathrm{Fa}$ & $\%$ & $p$ & $\mathrm{Fa}$ & $\%$ & $\mathrm{Fa}$ & $\%$ \\
\hline Muito Bom & 2 & 2.4 & ${ }^{*} 0.000$ & 19 & 23.2 & ${ }^{*} 0.008$ & 7 & 8.5 & ${ }^{*} 0.000$ & 24 & 29.3 & 52 & 15.9 \\
\hline Bom & 24 & 29.3 & & 35 & 42.7 & & 42 & 51.2 & & 49 & 59.8 & 150 & 45.7 \\
\hline $\begin{array}{c}\text { Nem Bom Nem } \\
\text { Ruim }\end{array}$ & 28 & 34.1 & & 20 & 24.4 & & 25 & 30.5 & & 7 & 8.5 & 80 & 24.4 \\
\hline Ruim & 24 & 29.3 & & 7 & 8.5 & & 7 & 8.5 & & 1 & 1.2 & 39 & 11.9 \\
\hline Muito Ruim & 4 & 4.9 & & 1 & 1.2 & & 1 & 1.2 & & 1 & 1.2 & 7 & 2.1 \\
\hline Total & 82 & 100.0 & & 82 & 100.0 & & 82 & 100.0 & & 82 & 100.0 & 328 & 100.0 \\
\hline
\end{tabular}

${ }^{*} \mathrm{p}<0.05\left(\mathrm{X}^{2}\right)$

$\mathrm{Na}$ Figura 8 é apresentado 0 valor médio de $L_{\text {Aeq }}$ de cada parque correlacionando-os com a "avaliação positiva" (opções "boa" e/ou "muito boa" agrupadas) da qualidade do ambiente sonoro. Portanto, constata-se que para um parque possuir uma boa qualidade da paisagem sonora (> $80 \%$ ) deve apresentar uma média de níveis de pressão sonora não superior a $55 \mathrm{~dB}(\mathrm{~A})$, como foi o caso apenas do parque Bacacheri.

Deste modo, verifica-se que a qualidade da paisagem sonora está principalmente relacionada com o contexto urbano de um parque, fator que influencia na propagação e percepção do som e, consequentemente, o incômodo ao ruído. O Parque Bacacheri (área controle), único com boa qualidade do ambiente sonoro $(>80 \%)$, se localiza em uma área estritamente residencial, mais longe do centro da cidade e de vias de intenso tráfego viário. Já os demais parques localizamse muito próximos e/ou cercados por vias de grande circulação de automotores, principais agentes de ruído e incômodo nestes espaços. 


\section{A PERCEPÇÃO DOS PRATICANTES DE ATIVIDADE FÍSICA SOBRE A QUALIDADE AMBIENTAL SONORA DOS PARQUES PÚBLICOS DE CURITIBA-PARANÁ}

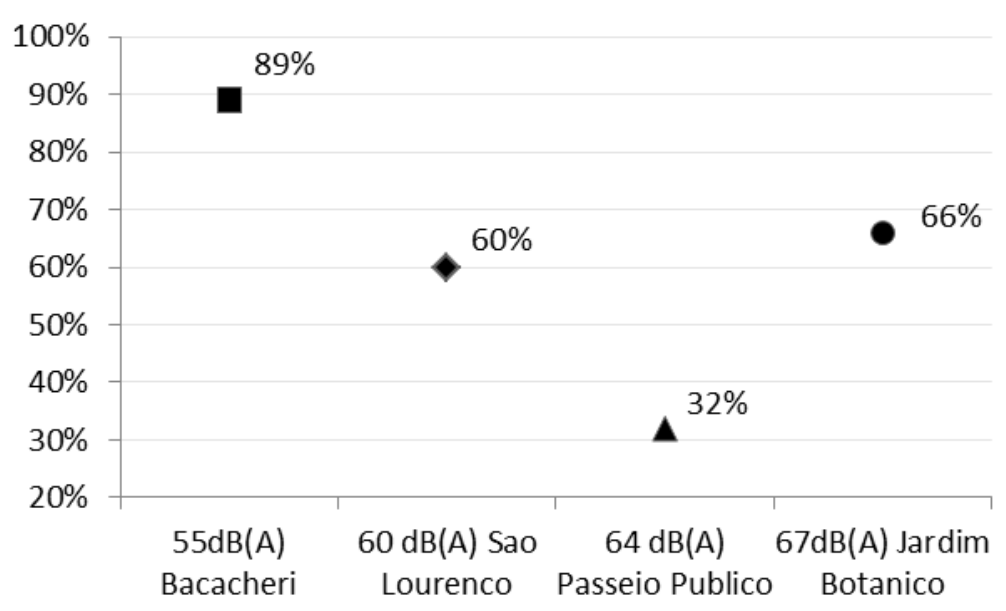

Figura 8: Qualidade do ambiente sonoro e valores médios de $L_{\text {Aeq }}$

Apesar disso, o Jardim Botânico apresenta maior proporção de usuários que julgaram positivamente o ambiente sonoro em comparação aos demais parques com este contexto urbano (São Lourenço e Passeio Público). Portanto, esta diferença pode ter ocorrido porque é o parque da pesquisa que possui a maior área útil. Ou seja, embora apresentar o valor médio mais elevado de $L_{\text {Aeq }}(67 \mathrm{~dB}[\mathrm{~A}]$ ) pode proporcionar uma maior distância dos usuários em relação às vias do entorno imediato (fontes de ruído e incômodo), dependendo da região em que estes circulam ou permanecem, e facilitar a percepção de sons agradáveis provindos do interior do parque, como os sons da natureza. O contrário acontece no Passeio Público porque tem a menor área útil entre os parques, ajudando então explicar o elevado número de frequentadores que se incomodaram "muito" e "extremamente" com o ruído e, consequentemente, a pior qualidade do ambiente acústico entre as áreas pesquisadas.

Uma vez que, como comentado anteriormente, fontes sonoras consideradas agradáveis, principalmente como os sons da natureza, podem proporcionar uma melhor impressão dos sujeitos em relação à qualidade do ambiente sonoro. Nos ambientes do São Lourenço e do Passeio Público, por exemplo, os sons mecânicos (desagradáveis) foram relativamente mais ouvidos do que os sons da natureza, 


\section{A PERCEPÇÃO DOS PRATICANTES DE ATIVIDADE FÍSICA SOBRE A QUALIDADE AMBIENTAL SONORA DOS PARQUES PÚBLICOS DE CURITIBA-PARANÁ}

embora a maioria dos usuários tenha identificado com frequência os dois tipos de sons. Já no Jardim Botânico estas duas fontes sonoras foram ouvidas com a mesma frequência. Portanto, este equilíbrio na identificação entre estes dois tipos de sons parece ter contribuído para uma melhor qualidade do ambiente sonoro neste parque, mesmo com um valor médio de $L_{\text {Aeq }}$ mais elevado.

Estas evidências demonstram mais uma vez a necessidade da conservação de sons que se revelam preferidos e/ou agradáveis para a adequação de uma melhor qualidade da paisagem sonora, reforçando que a estética do som ou semântica (significado do som para o ouvinte) são bastante relevantes para um projeto acústico ideal destes ambientes, que devem possuir propriedades atrativas para a comunidade (IRVINE, 2009; SZEREMETA \& ZANNIN, 2009). Desta forma, evidencia-se a necessidade de conservação da biodiversidade destas áreas e o controle do ruído ambiental para conservar e maximizar o contato com os sons da natureza.

Outros fatores que parecem ter influenciado na percepção dos frequentadores foram a paisagem visual e as suas expectativas em relação ao ambiente sonoro. Estudos em ambientes urbanos e laboratórios mostram que uma percepção positiva da paisagem visual ajuda as pessoas a perceberem de melhor forma o meio acústico em que estão inseridas (VIOLLON, 2002; YANG \& KANG, 2005a; SZEREMETA \& ZANNIN, 2009). Neste estudo, a beleza da paisagem visual foi um dos principais motivos para visitar os parques, principalmente no Jardim Botânico. Além disso, os ambientes do Bacacheri (área controle) e Jardim Botânico obtiveram um maior percentual de entrevistados, em relação aos demais parques, que concordaram que a paisagem sonora do parque combinava com a paisagem visual. Do mesmo modo foram as áreas com o maior número de usuários que admitiram que os sons que ouviram no parque estavam de acordo com que esperavam. Assim estes fatores parecem também ter corroborado para que ambos os parques apresentassem uma melhor qualidade do ambiente sonoro em relação às outras áreas. 


\section{A PERCEPÇÃO DOS PRATICANTES DE ATIVIDADE FÍSICA SOBRE A QUALIDADE AMBIENTAL SONORA DOS PARQUES PÚBLICOS DE CURITIBA-PARANÁ}

Desta forma, constata-se que a associação entre o contexto urbano, os níveis de pressão sonora, a composição do ambiente sonoro (sons agradáveis e desagradáveis) e a tipologia (dimensões da área e paisagem) de um parque pode influenciar no conforto acústico. Estas informações são de relevante importância para o projeto urbano, adequando a estrutura e localização de um parque a um maior conforto ambiental (HOKAO, 2004; IRVINE, 2009; SZEREMETA \& ZANNIN, 2009) e, assim, ajudar a estimular a sua utilização para a atividade física e o lazer. Pois áreas com melhores qualidades do ambiente têm maior potencial de uso (CASSOU, 2009). Portanto a avaliação e manejo do ambiente sonoro são complexos e, por isso, devem envolver profissionais de diferentes ciências para a promoção de ambientes com melhores qualidades e assim mais propícios ao desenvolvimento de atividades ligadas a saúde e qualidade de vida.

Perfil de Atributos do Ambiente Sonoro

Os entrevistados também avaliaram o ambiente sonoro no momento da entrevista, por 30 segundos, considerando-se oito atributos (quatro positivos e quatro negativos, opostos por pares, constituintes de quatro escalas bipolares de quatro pontos que foram dicotomizadas para a análise). Os resultados corroboram com os dados anteriores sobre a qualidade da paisagem sonora. A Figura 9 mostra que o perfil da área controle (Bacacheri), única com boa qualidade do ambiente sonoro, destaca-se das demais áreas porque os atributos positivos (agradável, calmo, empolgante e quieto) apresentam valores (\%) muito superiores aos dos índices de atributos negativos (desagradável, agitado, monótono e barulhento). 


\section{A PERCEPÇÃO DOS PRATICANTES DE ATIVIDADE FÍSICA SOBRE A QUALIDADE AMBIENTAL \\ SONORA DOS PARQUES PÚBLICOS DE CURITIBA-PARANÁ}

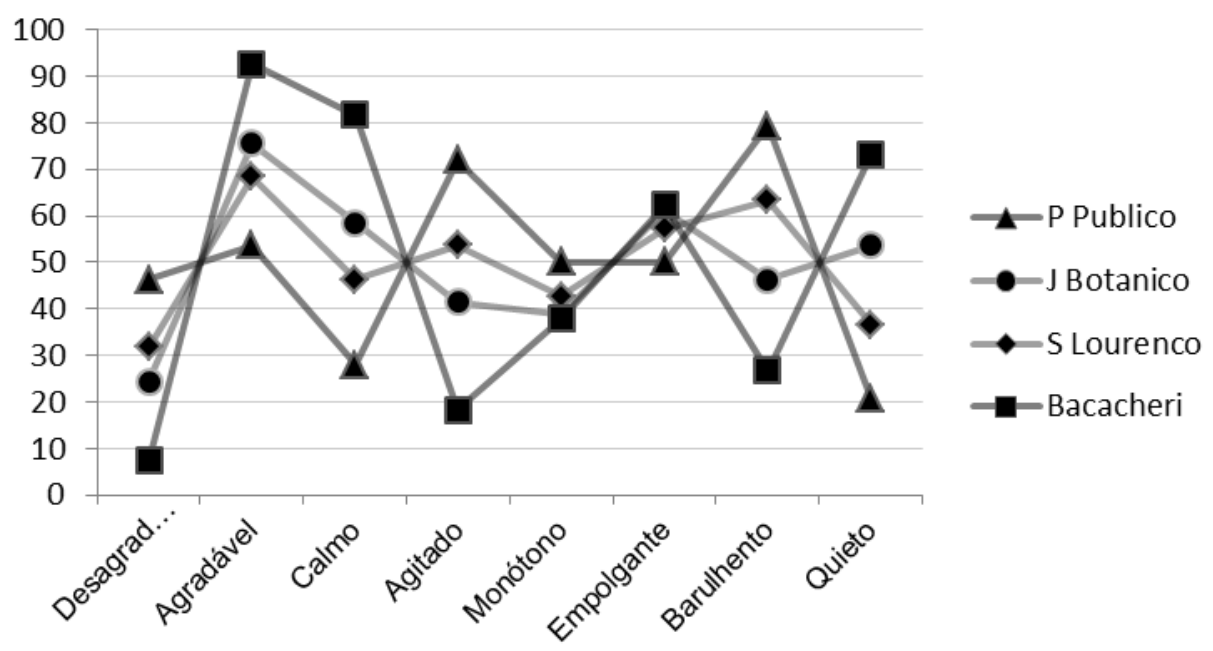

Figura 9: Atributos do ambiente sonoro (\%)

Entre os demais parques, o Jardim Botânico apresenta os valores mais elevados nas qualidades positivas e os mais baixos nas negativas, ressaltando que foi o parque com a segunda melhor avaliação na escala de qualidade do ambiente sonoro, precedido pela área controle, apesar dos elevados níveis sonoros. Também mostra perfil similar ao do Bacacheri, com todos os atributos positivos com índices mais elevados que os negativos, porém, com diferenças bem menores entre estes valores.

Os parques São Lourenço e Passeio Público apresentam um perfil parecido. Excepcionalmente, nestes espaços, os atributos negativos "agitado" e "barulhento" obtiveram maiores valores (\%) que seus pares positivos. Dentre todos os parques, o Passeio Público apresenta os índices (\%) mais elevados nas qualidades negativas e os mais baixos nas positivas, confirmando-o como o parque com a pior qualidade do ambiente sonoro.

\section{CONCLUSÕES}

Quanto aos dados acústicos, observou-se que os parques Jardim Botânico, Passeio Público e São Lourenco, situados muito próximos de vias de intenso tráfego de veículos, apresentaram valores médios de $L_{\text {Aeq }}$ acima do limite permitido (> 55 


\section{A PERCEPÇÃO DOS PRATICANTES DE ATIVIDADE FÍSICA SOBRE A QUALIDADE AMBIENTAL SONORA DOS PARQUES PÚBLICOS DE CURITIBA-PARANÁ}

$\mathrm{dB}[\mathrm{A}]$ ) pela legislação municipal. Portanto, considerados acusticamente poluídos. Apenas o parque Bacacheri, localizado mais distante do centro da cidade e único que está num contexto geográfico urbano mais afastado destas vias, apresentou valor médio de $L_{\text {Aeq }}(=55 \mathrm{~dB}$ ) de acordo com a lei do município. Ainda, tanto pelo mapeamento sonoro quanto pelas medições acústicas, verificou-se que as regiões dos parques mais próximas dos seus perímetros apresentam $L_{\text {Aeq }}$ mais elevados do que as áreas mais distantes. Assim, observa-se que principalmente devido a forma urbana do entorno o ruído ambiental influencia de forma negativa o ambiente de parques urbanos. Neste sentido, um maior afastamento de vias de elevado tráfego rodoviário - considerando-se 0 contexto urbano do parque e/ou melhor posicionamento das estruturas de lazer e atividade física - , pode promover um melhor conforto acústico. Os resultados referentes à percepção sonora auxiliam nesta constatação, já que apenas a área controle (parque Bacacheri) apresentou uma boa qualidade do ambiente sonoro.

Em relação a percepção ambiental e sonora evidenciou-se que: a) Em todas as áreas acusticamente poluídas ( $>55 \mathrm{~dB}$ ), de acordo com a legislação da cidade, os entrevistados ouviram mais frequentemente os sons mecânicos (tecnológicos) e se incomodaram mais com o ruído de trânsito do que os indivíduos da área controle (Bacacheri), com diferenças significativas em relação a mesma para estas variáveis. Assim, apenas o parque Bacacheri apresentou uma boa qualidade do ambiente sonoro, conforme o critério utilizado, ou seja, mais de $80 \%$ dos usuários perceberam a paisagem sonora positivamente. Estes achados demonstram que a qualidade do ambiente sonoro esta principalmente relacionada com os níveis de pressão sonora em razão do contexto urbano de um parque. Ainda mostram que um valor médio de $L_{\text {Aeq }}$ de até $55 \mathrm{~dB}(\mathrm{~A})$, como o da área controle, pode permitir um melhor conforto acústico. b) Foram ainda identificados, além do ruído ambiental, outros fatores ambientais e individuais dos usuários que parecem influenciar na percepção da qualidade da paisagem sonora em parques urbanos, como: a composição de tipos de sons da paisagem sonora, a beleza da paisagem visual e as expectativas dos usuários referentes aos sons. c) A paisagem sonora dos parques é caracterizada 


\section{A PERCEPÇÃO DOS PRATICANTES DE ATIVIDADE FÍSICA SOBRE A QUALIDADE AMBIENTAL SONORA DOS PARQUES PÚBLICOS DE CURITIBA-PARANÁ}

principalmente por sons da natureza e sons mecânicos, demonstrando a necessidade de projetos que visem a conservação dos sons naturais e o controle dos sons mecânicos para uma melhor qualidade do ambiente sonoro.

Estas evidências são importantes informações para um projeto urbano ideal, com o objetivo de proporcionar um melhor conforto no ambiente de parques públicos e, assim, também incentivar a utilização pelas comunidades. Deste modo, espera-se ajudar a possibilitar efetivamente a atividade física e o lazer nos grandes centros urbanos e, assim, promover um estilo de vida mais saudável para a população.

\section{AGRADECIMENTOS}

Os autores gostariam de agradecer aos revisores pelo seu trabalho em ajudar a melhorar a qualidade do presente artigo.

\section{REFERÊNCIAS}

ABNT - ASSOCIAÇÃO BRASILEIRA DE NORMAS TÉCNICAS. NBR-10.151: Avaliação do ruído em áreas habitadas visando o conforto da comunidade. Rio de Janeiro, 2000.

BAKER, E. A.; SCHOOTMAN, M.; KELLY, C.; BARNIDGE, E. Do Recreational Resources Contribute to Physical Activity? Journal of Physical Activity and Health, vol.5, pag. 252-261, 2008.

BARTON, J.; PRETTY, J. What is the Best Dose of Nature and Green Exercise for Improving Mental Health? A Multi-Study Analysis. Environ. Sci. Technol, 44, pag 3947-3955, 2010.

BAUMAN, A. E. Updating the evidence that physical activity is good for health: an epidemiological review 2000-2003. Journal of Science and Medicine in Sport 7, 6-19, 2004.

BEDIMO-RUNG A.; MOWEN A.; COHEN D. The significance of parks to physical activity and public health: a conceptual model. American Journal of Preventive Medicine. vol 28 (2 suppl 2) pag.159-168, 2005. 


\section{A PERCEPÇÃO DOS PRATICANTES DE ATIVIDADE FÍSICA SOBRE A QUALIDADE AMBIENTAL SONORA DOS PARQUES PÚBLICOS DE CURITIBA-PARANÁ}

BERLIN J. A; COLDITZ G. A. A Meta-Analysis of Physical Activity in the Prevention of Coronary Heart Disease. Am J Epidemiol, 132 (4): 612-628, 1990.

BLAIR S. N.; KOHL H. W.; BARLOW C.E. et al. Changes in physical fitness and allcause mortality: a prospective study of healthy and unhealthy men. JAMA, 273 (14): 1099-1105, 1995.

CASSOU, A. C. N. Características ambientais, Frequência de utilização e nível de atividade física dos usuários de parques e praças de Curitiba-PR. Curitiba. 130 p. Dissertação (Mestrado em Educação Física) - Universidade Federal do Paraná. 2009.

COHEN, D. A.; MCKENZIE T. L.; SEHGAL, A., WILLIAMSON, S.; GOLINELLI, D.; LURIE, N. Contribution of Parks to Physical Activity. American Journal of Public Health, vol. 97, pag. 509-514, 2007.

COHEN, D. A.; MARSH, T.; WILLIAMSON, S.; DEROSE, K. P.; MARTINEZ, H.; SETODJI, C.; MCKENZIE T.L. Parks and physical activity: Why are some parks used more than others? Preventive Medicine 50, S9-S12, 2010.

COLLET, C.; CHIARADIA, B. M.; REIS, R. S.; NASCIMENTO, J. V. Fatores Determinantes para a Realização de Atividades Físicas em Parque Urbano de Florianópolis. Revista Brasileira de Atividade Física \& Saúde, Vol. 13, № 1, 2008.

CURITIBA. Lei n. 10.625, de 19 de dezembro de 2002. Dispõe sobre ruídos urbanos, proteção do bem estar e do sossego público e dá outras providências.Câmara Municipal de Curitiba, Curitiba, 2002.

CASAS, W. J. P.; CORDEIRO, E. P.; MELLO, T. C.; ZANNIN, P. H. T. Noise mapping as a tool for controlling industrial noise pollution. Journal of Scientific \& Industrial Research, 73, 262-266, 2014.

DEPARTAMENTO DE TRÂNSITO DO GOVERNO DO ESTADO DO PARANÁDETRAN - Secretaria do Plantão de Acidentes do BPTran e Divisão de Estatística do DETRAN - Disponível em: <http://www.detran.pr.gov.br/arquivos/File/estatisticasdetransito/frotadeveiculoscada stradospr/2010/frotaVeiculoMunicipioAbril2010.pdf> Acesso em novembro de 2010 


\section{A PERCEPÇÃO DOS PRATICANTES DE ATIVIDADE FÍSICA SOBRE A QUALIDADE AMBIENTAL SONORA DOS PARQUES PÚBLICOS DE CURITIBA-PARANÁ}

FISHER K.J.; Li F.; MICHAEL Y.; CLEVELAND, M. Neighborhood-level influences on physical activity among older adults: a multilevel analysis. J Aging Phys Act, 12:4563, 2004.

FLECK, M. P. A. et al. Desenvolvimento da versão em português do instrumento de avaliação de qualidade de vida da OMS (WHOQOL-100). Revista Brasileira de Psiquiatria 21(1):19-28. 1999.

GOOGLE EARTH. Disponível em: http://www.google.com/earth/index.html. Acesso em 05/04/2010.

GUEDES, I. C. M.; BERTOLI, S. R.; ZANNIN, P. H. T. Influence of urban shapes on environmental noise: A case study in Aracajú - Brazil. Sci Total Environ, 412-413, 66-76, 2011.

HASKELL, W. L., I.-M. LEE, R. R. PATE, K. E. POWELL, S. N. BLAIR, B. A. FRANKLIN, C. A. MACERA, G. W. HEATH, P. D. THOMPSON, and A. BAUMAN. Physical Activity and Public Health: Updated Recommendation for Adults from the American College of Sports Medicine and the American Heart Association. Med. Sci. Sports Exerc. Vol. 39, № 8, pag. 1423-1434, 2007.

HOKAO, K. Research on the Sound Environment of Urban Open Space from the Viewpoint of Soundscape - A Case Study of Saga Forest Park, Japan. Acta Acustica United with Acustica. Vol.90, pag. 555-563, 2004.

HORNIG, E. F. Bringing Family Back to the Park. Parks \& Recreation, Jul. vol. 40, suppl. 7; pag. 46, 2005.

INSTITUTO BRASILEIRO DE GEOGRAFIA E ESTATÍSTICA - IBGE. População de Curitiba - Disponível em:<http://www.ibge.gov.br/cidadesat/topwindow.htm?1>. Acesso em Novembro de 2010.

IPPUC - Instituto de Pesquisa e Planejamento Urbano de Curitiba. - Curitiba Digital disponível em CD-ROM, edição 2006.

IPPUC - Instituto de Pesquisa e Planejamento Urbano de Curitiba. Mapas Temáticos (Físicos) - Disponível em: http://www.ippuc.org.br/. Acesso em Abril de 2014. 


\section{A PERCEPÇÃO DOS PRATICANTES DE ATIVIDADE FÍSICA SOBRE A QUALIDADE AMBIENTAL SONORA DOS PARQUES PÚBLICOS DE CURITIBA-PARANÁ}

IPPUC - Instituto de Pesquisa e Planejamento Urbano de Curitiba. Banco de Dados: Parques por Bairro, Regional e Localização em Curitiba, junho de 2013 - Disponível em: $<$ http://curitibaemdados.ippuc.org.br/Curitiba_em_dados_Pesquisa.htm>. Acesso em Abril de 2014.

IRVINE, K. N.; et al. Green space, soundscape and urban sustainability: an interdisciplinary, empirical study. Local Environment Vol. 14, No. 2, pag. 155-172, February 2009.

ISO - INTERNATIONAL ORGANIZATION STANDARTIZATION. ISO 1996-1, Acoustics - Description and measurement of environments noise - Part 1: Basic quanties and procedures. Geneva, 1996.

ISO - INTERNATIONAL ORGANIZATION STANDARTIZATION. ISO 1996-2, Acoustics - Description and measurement of environmental noise - Part 2: Acquisition of data pertinent to land use. Geneva, 1996.

JEON, J. Y; LEE, P. J.; YOU, J. Perceptual assessment of quality of urban soundscapes with combined noise sources and water sounds. J. Acoustic. Soc. Am. 127 (3), March 2010.

KOHL, H. W. Physical activity and cardiovascular disease: evidence for a dose response. Medicine and Science in Sports and Exercise, 33, S472-83; discussion S493-4, 2001.

KING, E. A.; RICE, H. J. The development of a practical framework for strategic noise mapping. Appl Acoust 70, 1116-27, 2009.

MENEZES, C. L. Desenvolvimento urbano e meio ambiente: a experiência de Curitiba. Campinas: Papirus, 1996.

NILSSON, M.E.; BERGLUND, B. Soundscape quality in suburban green areas and city parks. Acta Acustica united with Acustica 92, pag. 903-911, 2006.

PAYNE, S.R.; DEVINE-WRIGHT, P.; IRVINE, K. N.. People's perceptions and classifications of sounds heard in urban parks: semantics, affect and restoration. Inter-noise 2007: global approaches to noise control. 28-31 Istanbul, Turquia. August. 2007. 


\section{A PERCEPÇÃO DOS PRATICANTES DE ATIVIDADE FÍSICA SOBRE A QUALIDADE AMBIENTAL SONORA DOS PARQUES PÚBLICOS DE CURITIBA-PARANÁ}

PAZ, E. C. da; FERREIRA, A. M. C.; ZANNIN, P. H. T. Estudo comparativo da percepção do ruído urbano. Revista Saúde Pública [online], vol.39, n.3, 2005.

PEREIRA, M. Percepção Sonora no Espaço Público: Indicadores de Tolerância ao Ruído na Cidade do Rio de Janeiro. Anais do ENCAC - ELACAC 2003, Curitiba, PARANÁ, Brasil - 5 a 7 de novembro, 2003.

PINTO, F.A.C.; MARDONES, M.D.M. Noise mapping of densely populated neighborhoods - example of Copacabana Rio de Janeiro - Brazil. Environ Monit Assess 155:309-18, 2009.

REIS, R. S. Determinantes Ambientais para a Realização de Atividades Físicas nos Parques Urbanos de Curitiba: Uma Abordagem Sócio Ecológica da Percepção dos Usuários. Florianópolis. 101 p. Dissertação (Mestrado em Educação Física) - Centro de Desportos da Universidade Federal de Santa Catarina. 2001.

SALLIS, J.; CERVERO R.B, ASCHER, W.; HENDERSON, K. A.; M. KRAFT, K.; KERR, J. An Ecological Approach to Creating Active Living Communities. Annual Review of Public Health; Vol.27, pag.297-322, 2006.

SMMA - Secretaria Municipal do Meio Ambiente de Curitiba. Áreas Verdes. Disponível em: http://www.curitiba.pr.gov.br/conteudo/parques-e-bosques-smmasecretaria-municipal-do-meio-ambiente/267, acessado em 11/07/2010.

SMMA - Secretaria Municipal do Meio Ambiente de Curitiba. Plano de Manejo. Disponível em: http://www.curitiba.pr.gov.br/conteudo/plano-de-manejo-smmasecretaria-municipal-do-meio-ambiente/322, acessado em 15/04/2012.

SATO, T.; YANO, T.; BJORKMAN, M.; RYLANDER, R. Road traffic noise annoyance in relation to average noise level, number of events and maximum noise level. Journal of Sound and Vibration, Inglaterra, v. 223, n. 5, pag. 775-784, 1999.

SCHAFER, M. A Afinação do Mundo. Editora UNESPE, São Paulo.384p. 2001.

SZEREMETA, B; ZANNIN, P. H. T. Analysis and evaluation of soundscapes in public parks through interviews and measurement of noise. Science of Total Environment, 497, 6143-6149, 2009. 


\section{A PERCEPÇÃO DOS PRATICANTES DE ATIVIDADE FÍSICA SOBRE A QUALIDADE AMBIENTAL SONORA DOS PARQUES PÚBLICOS DE CURITIBA-PARANÁ}

SECRETARIA MUNICIPAL DO ESPORTE, LAZER E JUVENTUDE. Academia ao Ar Livre. Disponível em: http://www.curitiba.pr.gov.br/conteudo/academia-ao-ar-livresmelj-secretaria-municipal-do-esporte-lazer-e-juventude/144, acessado em $15 / 04 / 2012$.

TESTER, J.; BAKER, R. Making the playfields even: Evaluating the impact of an environmental intervention on park use and physical activity. Preventive Medicine 48, 316-320, 2009.

YANG, W.; KANG, J. Acoustical comfort evaluation in urban open public spaces. Applied Acoustics, v. 66, pag. 211-229, 2005.

YANG, W; KANG, J. Soundscape and sound preferences in urban squares: A case study in Sheffield. Journal of Urban Design, 10, 61-80, 2005.

WARBURTON, D.E.; NICOL, C.W.; BREDIN, S.S. Health benefits of physical activity: the evidence. Can Med Assoc J., vol. 174, pag. 802-809, 2006.

VIOLLON S.; LAVANDIERA C.; DRAKEB C. Influence of visual setting on sound ratings in an urban environment. Appl Acoust 63:493-511. 2002.

ZANNIN, P. H. T.; SZEREMETTA, B. Avaliação da poluição sonora no parque Jardim Botânico de Curitiba, Paraná, Brasil, Cad Saude Publica, 19(2) 683-686, 2003.

ZANNIN, P. H. T.; FERREIRA, A.M.C.; SZEREMETA, B. Evaluation of noise pollution in urban parks. Environmental Monitoring an Assessment, 118, 423-433, 2006.

ZANNIN, P. H. T.; SANT'ANA, D. Q. Noise mapping at different stages of a freeway redevelopment project - A case study in Brazil. Applied Acoustics, 72, 479-486, 2011.

ZANNIN, P. H. T.; ENGEL, M. S.; FIEDLER, P.E.K.; BUNN, F. Characterization of environmental noise based on noise measurements, noise mapping and interviews: A case study at a university campus in Brazil. Cities, 31, 317-327, 2013. 